\title{
Bidirectional Effects of Fentanyl on Dendritic Spines and AMPA Receptors Depend Upon the Internalization of $\mathrm{Mu}$ Opioid Receptors
}

\author{
Hang Lin ${ }^{1,2}$, Paul Higgins', Horace H Loh ${ }^{3}$, Ping-Yee Law ${ }^{3}$ and Dezhi Liao*, I \\ 'Department of Neuroscience, The University of Minnesota, 321 Church St S.E., Minneapolis, MN, USA; ${ }^{2}$ Department of Neurology, Chengdu \\ General Military Hospital, Chengdu City, China; ${ }^{3}$ Department of Pharmacology, The University of Minnesota, 32 I Church St S.E., Minneapolis, \\ MN, USA
}

\begin{abstract}
Fentanyl is a frequently used and abused opioid analgesic and can cause internalization of mu opioid receptors (MORs). Receptor internalization modulates the signaling pathways of opioid receptors. As changes in dendritic spines and synaptic AMPA receptors play important roles in addiction and memory loss, we investigated how fentanyl affects dendritic spines and synaptic AMPA receptors in cultured hippocampal neurons. Fentanyl at low concentrations $(0.01$ and $0.1 \mu \mathrm{M})$ caused the collapse of dendritic spines and decreased the number of AMPA receptor clusters. In contrast, fentanyl at high concentrations ( 1 and $10 \mu \mathrm{M}$ ) had opposite effects, inducing the emergence of new spines and increasing the number of AMPA receptor clusters. These dose-dependent bidirectional effects of fentanyl were blocked by a selective MOR antagonist CTOP at $5 \mu \mathrm{M}$. In neurons that had been transfected with HA-tagged or GFP-tagged MORs, fentanyl at high concentrations induced persistent and robust internalization of MORs, whereas fentanyl at lower concentrations induced little or transient receptor internalization. The blockade of receptor internalization with the expression of dominant-negative Dynamin I (the K44E mutant) reversed the effect of fentanyl at high concentrations, supporting a role of receptor internalization in modulating the dose-dependent effects of fentanyl. In contrast to morphine, the effects of fentanyl on dendritic spines are distinctively bidirectional and concentration dependent, probably due to its ability to induce robust internalization of MORs at high concentrations. The characterization of the effects of fentanyl on spines and AMPA receptors may help us understand the roles of MOR internalization in addiction and cognitive deficits.
\end{abstract}

Neuropsychopharmacology (2009) 34, 2097-2 I I ; do: I 0. I038/npp.2009.34; published online I8 March 2009

Keywords: fentanyl; dendritic spines; AMPA receptors; receptor internalization; cognitive dysfunctions

\section{INTRODUCTION}

Behavioral sensitization to psychostimulants was prevented when NMDA receptor antagonist MK-801 was administered before injection of cocaine and amphetamine (Karler et al, 1989) or when MK-801 was microinjected into the ventral tegmental area (VTA) or amygdala (Kalivas and Alesdatter, 1993). The tolerance and sensitization of opiates were also inhibited by treatment of MK-801 before opiate exposure (Trujillo and Akil, 1991; Wolf and Jeziorski, 1993). NMDA receptors are required for synaptic plasticity and, therefore, opioid-induced plasticity of dendritic spines is likely to play some roles in drug addiction. These pioneer studies lead to the widely accepted hypothesis that drug addiction is a

\footnotetext{
*Correspondence: Dr D Liao, Department of Neuroscience, The University of Minnesota, 32I Church St S.E. Minneapolis, MN 55455, USA, Tel: + 612626 3522, Fax: + 6126265009 ,

E-mail: liaox020@umn.edu

Received 14 October 2008; revised 5 February 2009; accepted 6 February 2009
}

neural plasticity-dependent pathological form of learning and memory (Kauer and Malenka, 2007; Kelley, 2004; Nestler, 2002; Williams et al, 2001; Wolf, 2002).

A large amount of evidence shows that chronic opioid use or abuse leads to impairment of cognitive functions (Ersche et al, 2006; Bodnar, 2007; Gruber et al, 2007; Mintzer et al, 2005). The pyramidal cell layer of the hippocampus is one of the regions that have the highest level of MOR proteins (Arvidsson et al, 1995) and MOR mRNA (Mansour et al, 1995). The pyramidal neurons are glutamatergic neurons with numerous dendritic spines that contain AMPA receptors and NMDA receptors (Hollmann and Heinemann, 1994; Kennedy, 2000). Synaptic plasticity of dendritic spines has been proposed to be the cellular basis for experiencedependent learning and memory for decades (Bliss and Collingridge, 1993; Malenka, 1994; Martin et al, 2000). Chronic administration with morphine profoundly decreases the density of dendritic spines in the hippocampus in rats that self-administered morphine (Robinson et al, 2002; this group of rats repeatedly took morphine, resulting 
in long-time continuous exposure of morphine). Chronic treatment with morphine also caused collapse of dendritic spines in cultured hippocampal neurons (Liao et al, 2005). Therefore, chronic opioid exposure may cause cognitive deficits via MOR-mediated aberrations in dendritic spines and synaptic AMPA receptors.

Fentanyl is one of the most popular opioid analgesics for patients undergoing surgery or suffering from chronic pain (Stanley, 1992, 2005; Skaer, 2004, 2006). Overdose of 'killer fentanyl' in opioid addicts has caused grave concerns in public health and safety (Fodale et al, 2008). Despite the extensive use and abuse of fentanyl, it is still not known whether synthetic opioids such as fentanyl have the same pharmacological effect on excitatory synapses as naturally derived opiates such as morphine. In this study, unlike morphine, fentanyl at a low concentration decreases the density of spines and AMPA receptor clusters whereas at a high concentration it increases the density of spines and AMPA receptor clusters. In our previous studies, naloxone and genetic deletion of MORs in transgenic mice increased the density of dendritic spines, suggesting that MORmediated tonic inhibition of spinogenesis may play an important role in maintaining the normal morphology of dendritic spines in mature neurons (Liao et al, 2005). In this study, we will test the hypothesis that fentanyl at a high concentration induces emergence of new spines by removing MOR-mediated tonic inhibition of spinogenesis via receptor internalization.

\section{MATERIALS AND METHODS}

\section{High-Density Neuronal Cultures and Neuronal Transfection}

A 25-mm glass polylysine-coated coverslip (thickness, $0.08 \mathrm{~mm}$ ) was glued to the bottom of a $35-\mathrm{mm}$ culture dish with a 22-mm hole using silicone sealant as previously described (Lin et al, 2004; Wiens et al, 2005). Dissociated neuronal cultures from rat hippocampus at postnatal days 1-2 were prepared as previously described (Liao et al, 2001). Primary hippocampal cultures were used, because the hippocampus is one of the regions that contain the highest level of MORs (Arvidsson et al, 1995) and has been implicated to be important for addiction (Vorel et al, 2001; Biala et al, 2005; Fan et al, 1999) as well as learning and memory (Malinow et al, 2000). Neurons were plated onto prepared 35$\mathrm{mm}$ culture dishes at a density of $1 \times 10^{6}$ cells per dish. The age of cultured neurons was counted from the day of plating, 1 day in vitro (DIV). Neurons at 5-7 DIV were transfected with appropriate plasmids using the standard calcium phosphate precipitation method as previously described (Lin et al, 2004). After transfection, neurons were put back to a tissue culture incubator $\left(37^{\circ} \mathrm{C}, 5 \% \mathrm{CO}_{2}\right)$ and allowed to mature and develop dendritic spines until $\sim 3$ weeks in vitro for usage. In cotransfections, several different plasmids were mixed together with the phosphate buffer and $\mathrm{CaCl}_{2}$ before being added to the culture media.

\section{Low-Density Neuronal Cultures}

To detect the distribution of endogenous synaptic proteins with high resolution, low-density neuronal cultures were prepared as previously described with some modifications (Liao et al, 1999). Dissociated neuronal cultures from rat hippocampus at postnatal days 1-2 were plated into 12-well culture plates at a density of 50000-100000 cells per well. Each well contained a polylysine-coated $12-\mathrm{mm}$ glass coverslip on the bottom. To maintain the low-density cultures for a long time ( $>1$ month), the above $12-\mathrm{mm}$ coverslips with low-density cultured neurons were transferred to $60 \mathrm{~mm}$ dishes (4 coverslips per dish; the coverslips faced up) that contained high-density neuronal cultures after 1 week in vitro. In previous studies, dishes with a glial feed layer were often used to support low-density cultures (Goslin and Banker, 1991). Recently, we found that highdensity neuronal cultures were far better supporters than pure glial cells, suggesting that neurons probably also play some roles in the survival of nearby neurons.

\section{Time-Lapse Live Imaging Method}

To label dendrites, high-density neurons at 5-7 DIV were transfected with plasmids encoding enhanced green fluorescence (GFP) or GFP-tagged molecules. The $35-\mathrm{mm}$ culture dishes fit tightly in a homemade holding chamber on a fixed platform above an inverted Nikon microscope sitting on an $\mathrm{X}-\mathrm{Y}$ translation stage (Burleigh Inc.). The location of any neuron of interest was recorded by the reading of the $\mathrm{X}-\mathrm{Y}$ translation stage. The culture dish was immediately put back into a tissue culture incubator after each observation. Neurons could be found again in the next observation using the $\mathrm{X}-\mathrm{Y}$ translation stage (accuracy, $4 \mu \mathrm{m}$ ). In addition, this $\mathrm{X}-\mathrm{Y}$ translation stage could also be used to find neurons after fixation and permeabilization (see the next paragraph for fixation method). To block the internalization of MORs, neurons were cotransfected with HA-tagged dominantnegative Dynamin I (the K44E mutant, referred to as Dyn-; Chu et al, 1997; Zhao et al, 2006) and GFP-tagged proteins. In these experiments, the $\mathrm{X}-\mathrm{Y}$ translation stage was particularly useful in locating neurons because the expression of HA-tagged Dynamin I in these neurons was detected using a mouse monoclonal anti-HA antibody (Covance, Richmond, CA) after fixation and permeabilization.

\section{Immunocytochemistry in Fixed Tissues}

A rabbit polyclonal antibody against the $\mathrm{N}$-terminus of GluR1 subunits of AMPA receptors was used to detect the surface AMPA receptors (see next paragraph for surface staining). Cultured neurons were fixed and permeabilized successively with $4 \%$ paraformaldehyde, $100 \%$ methanol, and $0.2 \%$ Triton X-100 (Liao et al, 1999). Commercial antibodies against synaptophysin (mouse monoclonal; Chemicon) and PSD95 (mouse monoclonal; Chemicon) were used as pre- and postsynaptic markers, respectively (Liao et al, 1999, 2001). Finally, FITC (green) or rhodamine (red)-conjugated secondary antibodies (Jackson ImmunoResearch) were used to recognize these primary antibodies.

\section{Live Surface Staining of N-GluR1 and HA-tag MOR-GFP}

The live surface staining of GluR1 subunits of AMPA receptors has been previously described (Liao et al, 1999; O'brien et al, 1998). A polyclonal rabbit antibody was made 
against the N-terminus of GluR1 subunits of AMPA receptors. Neurons at 21 DIV were treated with fentanyl at a concentration of 0 (untreated control), $0.01,0.1,1$, or $10 \mu \mathrm{M}$ for 3 days and, thereafter, were incubated with culture media that contained the anti-N-GluR1 antibody at $37^{\circ} \mathrm{C}$ in a tissue culture incubator for $1 \mathrm{~h}$. These neurons were incubated with a rhodamine-conjugated antibody diluted in $10 \%$ donkey serum for another $1 \mathrm{~h}$ in $37^{\circ} \mathrm{C}$ after fixation and permeabilization. These neurons were also costained with either the presynaptic marker synaptophysin or the postsynaptic marker PSD95. To measure fentanylinduced internalization of MORs, neurons were transfected with plasmids encoding MORs with an $\mathrm{HA}$ tag at the $\mathrm{N}$ terminus and a GFP tag at the C-terminus. Neurons at 21 DIV were treated with fentanyl at a concentration of $0,0.01$, $0.1,1$, or $10 \mu \mathrm{M}$ for $1 \mathrm{~h}$. A mouse monoclonal anti-HA antibody (Covance) was added to culture media that contained fentanyl (concentration unchanged) at $37^{\circ} \mathrm{C}$ for another $1 \mathrm{~h}$ (fentanyl treatment time $=2 \mathrm{~h}$ ). Rhodaminelinked secondary anti-mouse antibody was used to label the primary anti-HA antibody after the cultured neurons were fixed and permeabilized with $4 \%$ paraformaldehyde, methanol, and triton (Liao et al, 2007b).

\section{Image Analysis}

Time-lapse live images from the same neuron at 21 DIV were taken before and at various time points after drug treatments as previously described (Liao et al, 2005). All digital images were analyzed with MetaMorph Imaging System (Universal Imaging Co.). Unless stated otherwise, all images of live neurons were taken as stacks and were averaged into one image before further analysis. In addition to simple averaging, stacks of images were also processed by deconvolution analyses using the MetaMorph software with the nearest planes. A stack of deconvoluted images was further averaged into one single image. A dendritic protrusion with an expanded head that was 50\% wider than its neck was defined as a spine. The number of spines from a dendrite was manually counted and normalized per $100 \mu \mathrm{m}$ dendritic length. The intensity of fluorescence in the soma and individual dendrites was measured using the MetaMorph program (auto-threshold for bright objects) and further calibrated by nearby baseline area: calibrated fluorescence $=($ dendritic fluorescence-baseline $) /$ baseline. To quantify the endocytosis in neurons expressing HAMOR-GFP, the HA tag was sequentially stained with a primary anti-HA antibody and a rhodamine-labeled (red) secondary antibody. The ratio of red to green fluorescence in the same region was used to estimate the ratio of surface MOR/total MOR. Using another method to quantify endocytosis, the coefficient of variation (CV) was used to estimate the aggregation of MOR-GFP in dendrites. The CV values were estimated from un-deconvoluted images. A line (width $=3$ pixels; fluorescence intensities at the 3 pixels were averaged into 1 pixel) was manually drawn in the middle of a dendrite. The fluorescence intensities at all pixels of this line were read out using the 'line scan' program and all pixels were pooled together to calculate the coefficient of variation ( $\mathrm{CV}=$ standard deviation/mean). As $\mathrm{CV}$ reflects how variable the data in a sample are, a dendrite with relatively uniform MOR-GFP distribution should yield a low $\mathrm{CV}$ value. In contrast, a dendrite with aggregates of MOR-GFP should yield a high CV value. Student's $t$-tests were used for comparison between parameters from two groups whereas ANOVA tests were used for comparison between parameters from multiple groups $(n-$ number of neurons; $p<0.05$, significant). All data are reported as mean \pm standard error. ${ }^{*} p<0.05 ;{ }^{* *} p<0.01 ;{ }^{* *} p<0.001$.

\section{RESULTS}

\section{Fentanyl Causes Concentration-Dependent Bidirectional Changes in Dendritic Spines}

Chronic treatment with the MOR agonist morphine caused collapse of dendritic spines in cultured dissociated neurons (Liao et al, 2005). It is still not known whether synthetic opioids such as fentanyl have the same pharmacological effect on excitatory synapses as naturally derived opiates such as morphine. To determine how chronic treatment with fentanyl affects the morphology of dendritic spines, cultured dissociated rat hippocampal neurons were transfected with plasmids encoding the enhanced green fluorescence protein (GFP). Fentanyl at four concentrations $(0.01$, $0.1,1$, and $10 \mu \mathrm{M}$ ) was applied to GFP-labeled neurons at 21 DIV (Figure 1b-e) and untreated neurons were used as the control (Figure 1a). Time-lapse images were taken on dendrites before and 1 and 3 days after the application of fentanyl. Dendritic spines gradually shrunk and eventually disappeared in 1-3 days after treatment with fentanyl at low concentrations $(0.01$ or $0.1 \mu \mathrm{M}$; Figure $1 \mathrm{~b}$ and $\mathrm{c})$. These low concentrations of fentanyl significantly decreased the density of dendritic protrusions and spines after 1-3 days of treatment (Figure 1f and g; repeated measurement ANOVA test, comparing with before treatment; $n=8$ neurons in each group). In contrast, fentanyl at high concentrations ( 1 or $10 \mu \mathrm{M})$ induced the emergence of new dendritic spines (Figure 1d and e) and significantly increased the density of dendritic protrusions and spines after 1-3 days of treatment (Figure if and g). These results demonstrate that fentanyl can cause bidirectional effects on dendritic spines depending on the concentrations that are used.

To test whether fentanyl induces acute changes in dendritic spines, the density of dendritic spines were measured before and 2 and $4 \mathrm{~h}$ after treatment of fentanyl at 0.01 and $10 \mu \mathrm{M}$ whereas untreated neurons were used as the control (Figure $1 \mathrm{~h}$ ). Although fentanyl at $0.01 \mu \mathrm{M}$ causes obvious decreases in 4 out of 8 neurons after $4 \mathrm{~h}$ of treatment, these effects of fentanyl were not yet significant within $4 \mathrm{~h}$ (Figure $1 \mathrm{~h}$ and $\mathrm{i}$ ). Consistent with our previous studies (Liao et al, 2005), this result confirms that the temporal dynamics of MOR-mediated spine loss is slow. In contrast, fentanyl at $10 \mu \mathrm{M}$ significantly increased the density of dendritic spines after $4 \mathrm{~h}$ of treatment (Figure 1h and i).

\section{Fentanyl-Induced Bidirectional Changes Require the Participation of MORs}

Fentanyl is an opioid agonist that primarily activates MORs and can also activate delta opioid receptors (DORs) with a much lower affinity (Rang et al, 1995). To determine 


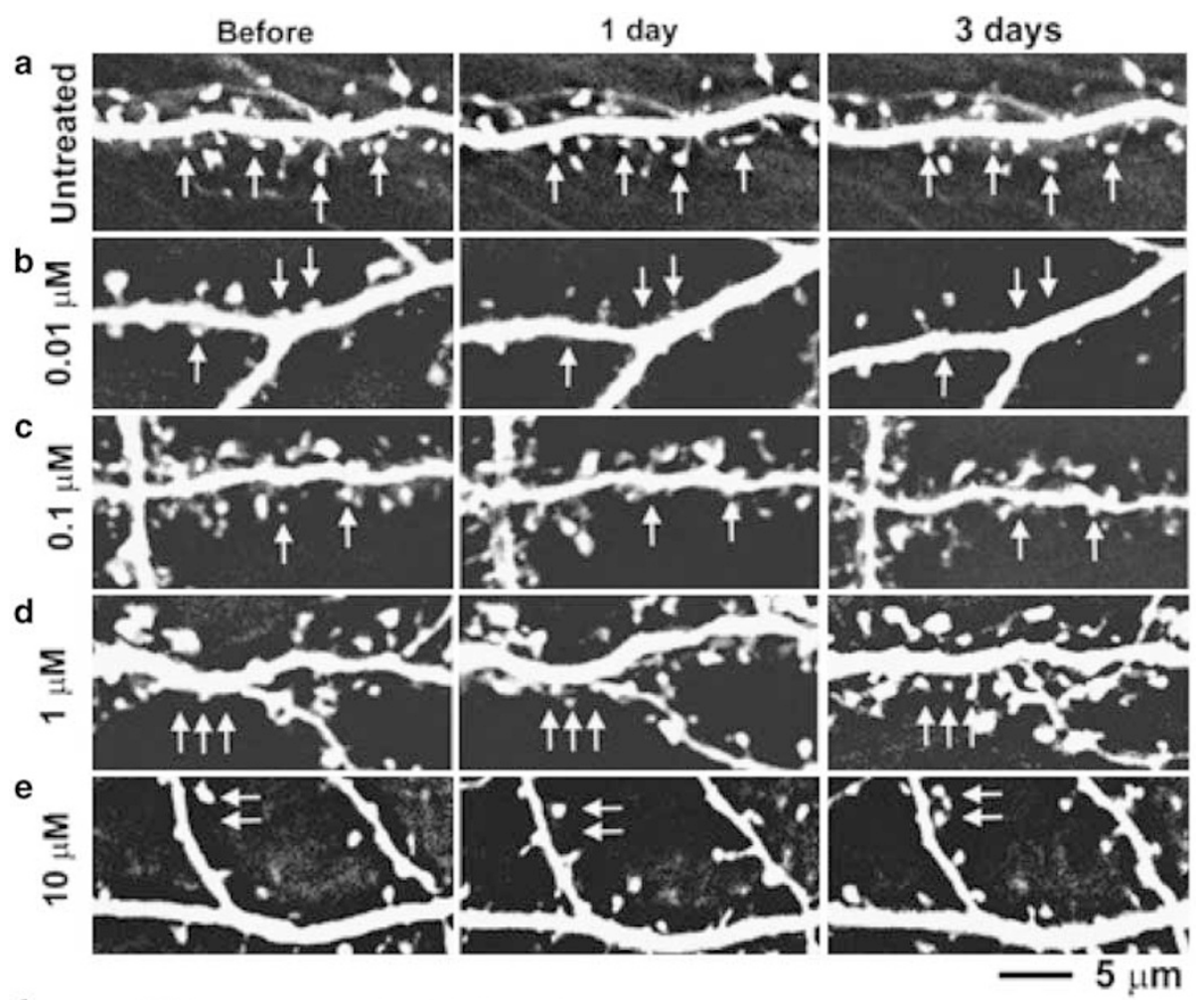

f

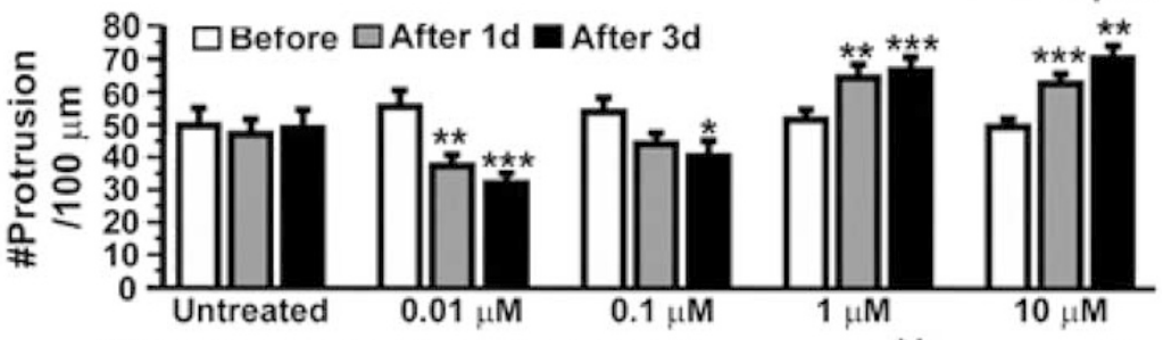

g
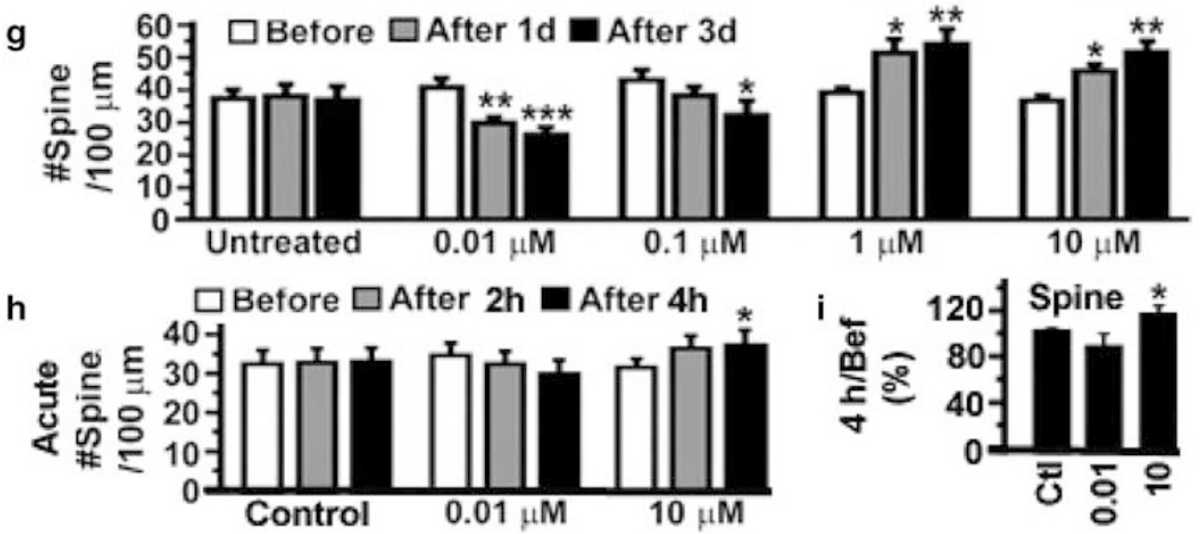

Figure I Fentanyl at a low concentration decreased the density of dendritic spines whereas fentanyl at a high concentration had an opposite effect. (a-e) Neurons expressing GFP were photographed before and I and 3 days after the application of fentanyl at various concentrations (untreated control, 0.0 I, $0.1, I$, and $10 \mu \mathrm{M} ; n=8$ neurons in each group). Arrows in (a): There was no obvious change in the number of dendritic spines even though the shape and size of individual spines were dynamically altered. We saw retraction and emergence of some spines, but the density of spines was largely unchanged in untreated mature neurons ( $>2$ I DIV). Arrows in ( $b$ and $c)$ : Dendritic spines gradually shrunk and eventually collapsed after treatment with fentanyl at low concentrations for $1-3$ days. Arrows in ( $d$ and e): Many new dendritic spines emerged after treatment with fentanyl at high concentrations. ( $\mathrm{f}$ and $g$ ) The densities of dendritic protrusions and spines (\# per I00 $\mu \mathrm{m}$ of dendrites) in five groups of neurons (left to right: untreated, $0.0 \mathrm{I}, 0.1, \mathrm{I}$, and $\mathrm{I} 0 \mu \mathrm{M}$ ) were quantified before (open) and I (gray) and 3 days (black) after treatment with fentanyl. A dendritic protrusion with an expanded head that was $50 \%$ wider than its neck was defined as a spine. (h) To measure the acute effects of fentanyl, neurons expressing GFP were photographed before and 2 and $4 \mathrm{~h}$ after the application of fentanyl at various concentrations (untreated control, $0.0 \mathrm{I}$, and $10 \mu \mathrm{M}$ ). The densities of dendritic spines were plotted at three time points in each experimental group and changes in spines after treatment were compared with those before treatment using repeated measurement ANOVA. (i) In each individual neuron, the density of spines after $4 \mathrm{~h}$ of treatment was normalized as percentage by the baseline value before treatment. The normalized changes in fentanyl-treated groups were compared with those in untreated control using one-way ANOVA. $* p<0.05 ; * * * 20.01$; **** $p<0.00$ I. 
whether the activation of MORs plays an important role in the fentanyl-induced bidirectional change in dendritic spines, a selective MOR antagonist, D-Phe-Cys-Tyr-D-TrpOrn-Thr-Pen-Thr-NH2 (CTOP), at $5 \mu \mathrm{M}$ was added to the media of cultured neurons and neurons were continuously treated with CTOP for 1 week. In the two testing groups, dynamic changes in dendritic protrusions and spines were monitored for 3 days after adding fentanyl at 0.01 and $10 \mu \mathrm{M}$, respectively, to the CTOP-containing neuronal media (Figure 2a-c). In the control group, neurons were continuously treated with CTOP alone (Figure 2a). The density of dendritic protrusions and spines was increased in all three experimental groups, suggesting that blockade of MORs by CTOP facilitates the emergence of new dendritic spines (Figure $2 \mathrm{~d}$ and f; consistent with Liao et al, 2005). In the presence of CTOP, fentanyl no longer induced dosedependent bidirectional changes in dendritic spines as the density of dendritic spines was increased in all three experimental groups (Figure $2 \mathrm{f}$ and $\mathrm{g}$ ). The increase in dendritic spines is probably due to the removal of MORmediated tonic inhibition of spinogenesis by CTOP (Liao et al, 2005; also see the model in Figure 9). The amount of increase in the densities of dendritic protrusions and spines in fentanyl-treated neurons was not significantly different from that in the control neurons, indicating that the effects of fentanyl were blocked in the presence of CTOP (Figure 2e and g). These results support that fentanyl-induced bidirectional changes in dendritic spines are mainly mediated via MORs.

\section{Fentanyl Causes Bidirectional Changes in Synaptic AMPA Receptors}

To test whether fentanyl can alter the function of excitatory synapses by regulating AMPA receptor trafficking, a polyclonal rabbit antibody against the N-terminus of GluR1

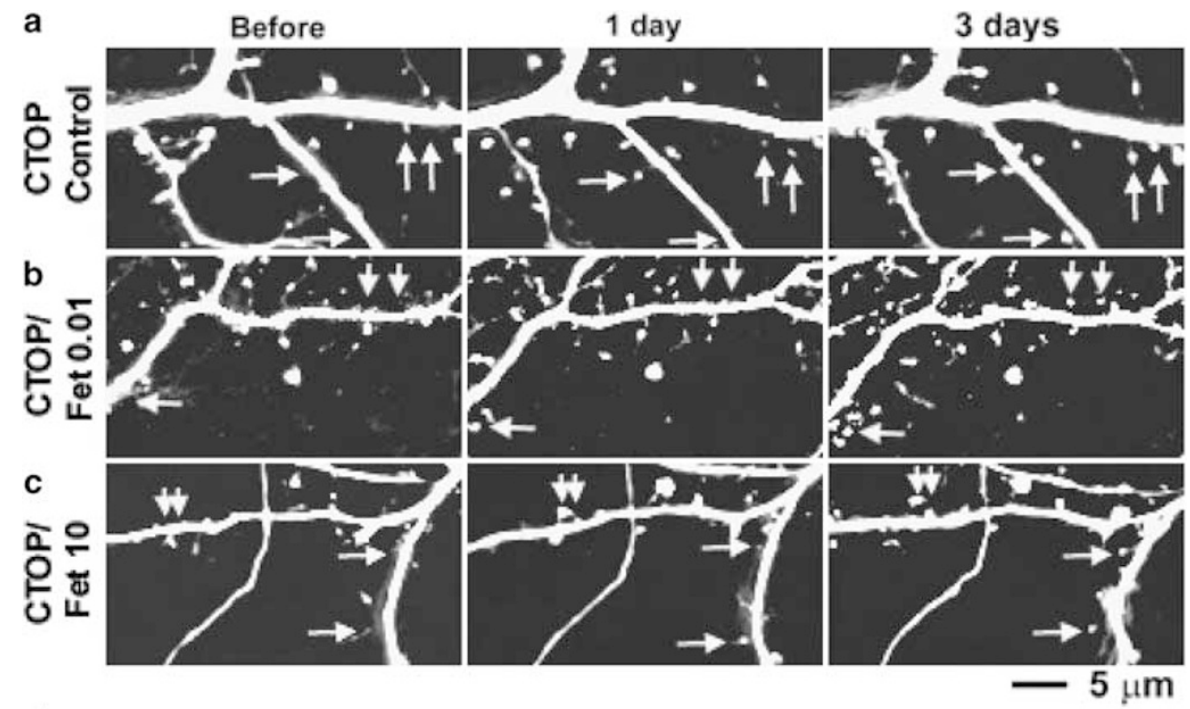

d
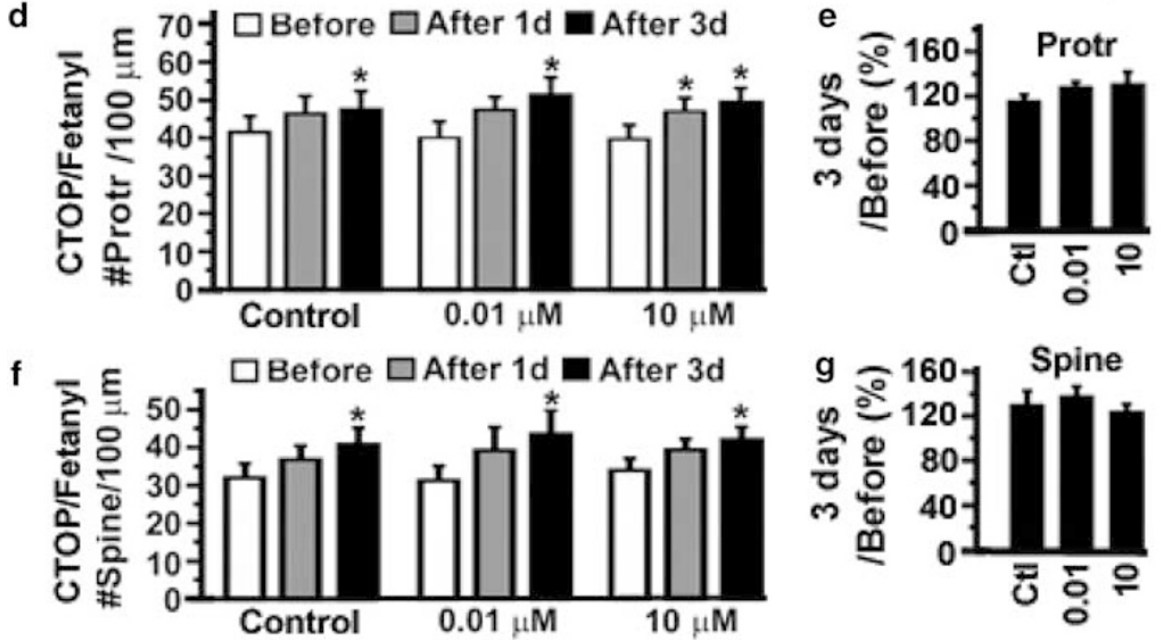

Figure 2 The bidirectional effects of fentanyl on the density of dendritic spines require the participation of MORs. (a-c) CTOP (5 $\mu$ M) was applied to cultured hippocampal neurons at I4 DIV to block MORs. In the continuous presence of CTOP for I week, neurons expressing GFP at 2I DIV were photographed before and I and 3 days after the addition of fentanyl at various concentrations ((a) control with CTOP alone; (b) fetanyl at 0.0 I $\mu$ M plus CTOP; (c) fentanyl at $10 \mu \mathrm{M}$ plus CTOP; $n=8$ neurons each group). Arrows denote emergence of new spines. ( $d$ and $f$ ) The densities of dendritic protrusions and spines (\# per $100 \mu \mathrm{m}$ of dendrites) in the above three groups of neurons were quantified before (open) and I (gray) and 3 days (black) after treatment with fentanyl. (e and g) In each individual neuron, the density of dendritic protrusions and spines after 3 days of treatment was normalized as percentage by the baseline value before treatment. There is no significant difference in the normalized percentage between the control (CTOP alone, left bar) and testing groups (CTOP + fentanyl $(0.0 \mathrm{I}$ and $10 \mu \mathrm{M})$, middle and left bars). ${ }^{*} p<0.05$; $* * p<0.01$; **** $p<0.00 \mathrm{I}$. 
subunits was used to recognize surface AMPA receptors (see Materials and Methods for details). Low-density cultured neurons were treated with fentanyl at 0 (control), $0.01,0.1,1$, and $10 \mu \mathrm{M}$ for 3 days and were costained with antibodies against $\mathrm{N}-\mathrm{GluR} 1$ and the presynaptic marker synaptophysin (Figure 3). In control neurons, intensely stained clusters of GluR1 subunits were distributed along dendrites and were colocalized with or adjacent to clusters of synaptophysin proteins (Figure 3a). Treatment with fentanyl at low concentrations $(0.01$ and $0.1 \mu \mathrm{M})$ reduced the size and fluorescence intensity of GluR1 clusters (Figure $3 \mathrm{~b}$ ) and significantly decreased the density of these clusters (Figure $3 \mathrm{~d}, n=10-11$ neurons in each group). In contrast, fentanyl at high concentrations $(1$ and $10 \mu \mathrm{M})$ had opposite effects, significantly increasing the density of GluR1 clusters (Figure $3 c$ and d). Treatment with fentanyl at all concentrations had no significant effects on the number of synaptophysin clusters (Figure 3d, black bars). Consequently, fentanyl at a low concentration $(0.01 \mu \mathrm{M})$ significantly decreased the proportion of synaptophysin clusters that colocalized with GluR1 clusters vs total number of synaptophysin clusters, whereas fentanyl at high concentrations $(1$ and $10 \mu \mathrm{M})$ increased this proportion. These results indicate that fentanyl causes no significant change in presynaptic elements but induces dose-dependent bidirectional changes in postsynaptic elements.

Postsynaptic density protein 95 (PSD95) is an NMDA receptor-anchoring protein that is abundant in the postsynaptic density of dendritic spines (Kennedy, 2000) and is widely used to label excitatory glutamatergic synapses. Lowdensity cultured neurons were treated with fentanyl at 0 (control), $0.01,0.1,1$, and $10 \mu \mathrm{M}$ for 3 days and were costained with antibodies against N-GluR1 and PSD95 (Figure 4). Consistent with previous results in Figure 3, treatment with fentanyl at low concentration $(0.01 \mu \mathrm{M})$ significantly decreased the density of GluR1 clusters whereas fentanyl at high concentrations ( 1 and $10 \mu \mathrm{M}$ ) had opposite effects (Figure $4 \mathrm{~d} ; n=10-12$ neurons in each group). Interestingly, in addition to altering the density of AMPA receptor clusters, treatment with fentanyl also a

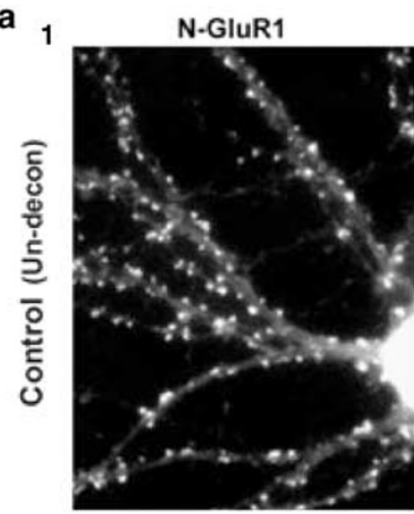

2
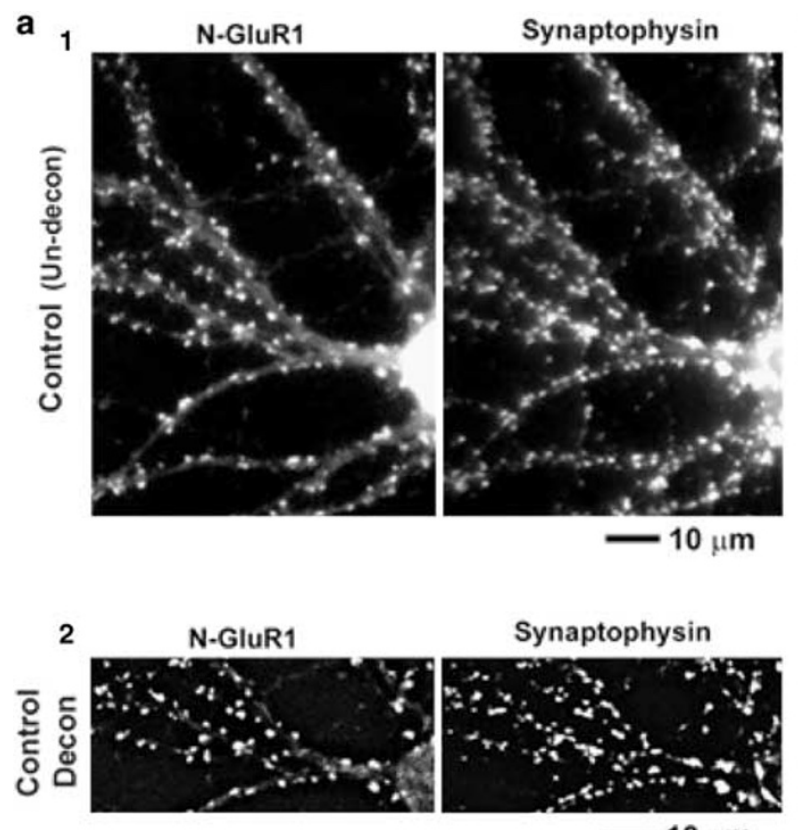

$-10 \mu \mathrm{m}$

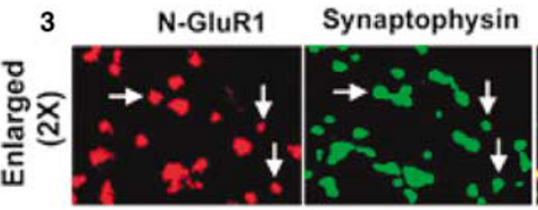



$10 \mu \mathrm{m}$
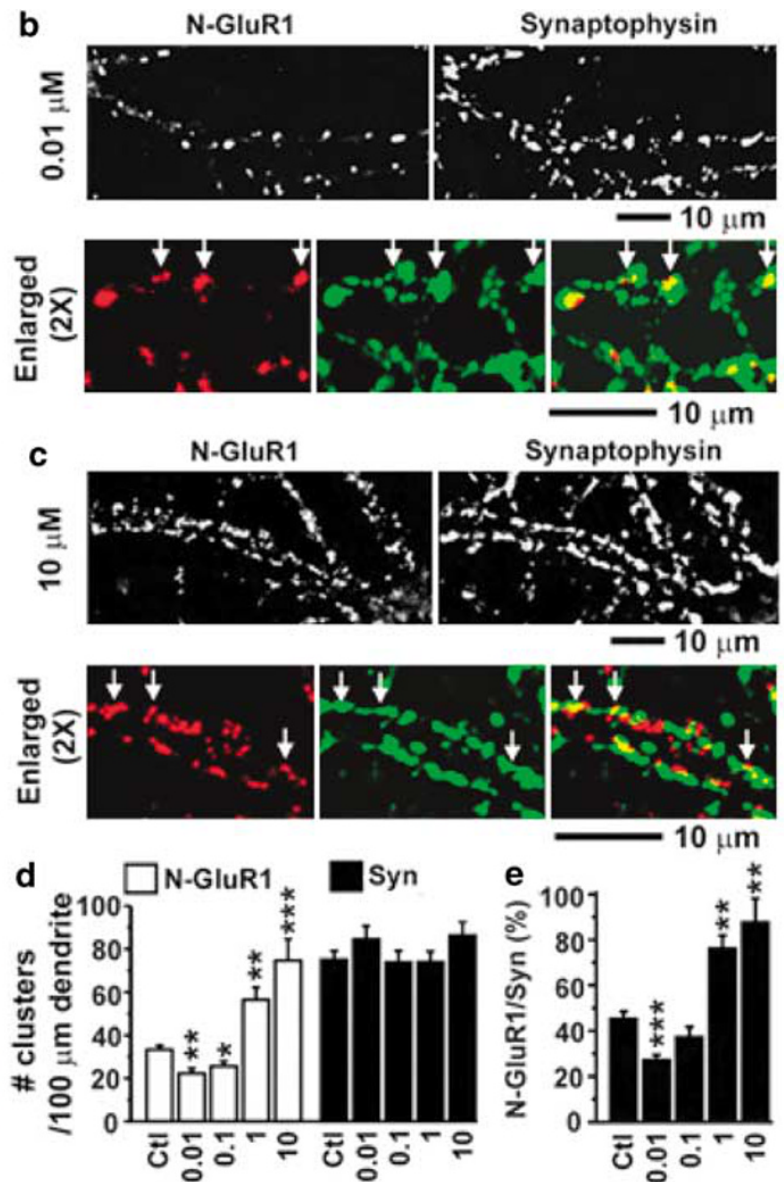

Figure 3 Effects of fentanyl on surface-synaptic AMPA receptors in low density cultured neurons. (al) An untreated control neuron that was costained with an antibody against the N-terminus of GluRI subunits of AMPA receptors (left, red) and an antibody against a presynaptic maker synaptophysin (right, green). The two images were simple averages of stacks of unprocessed images. (a2) The two images were from the same neuron as in al. They were averages of stacks of images that had been processed by deconvolution analyses using the MetaMorph software with the nearest planes. Note that the clusters were sharper after the deconvolution. (a3) The deconvoluted images of N-GluRI staining (left) and synaptophysin staining (middle) were enlarged by two times and pseudocolorized to examine the colocalization (right). (b and c) Neurons costained with antibodies against N-GluRI and synaptophysin that had been treated with fentanyl at low $(0.01 \mu \mathrm{M})$ and high concentrations $(10 \mu \mathrm{M})$, respectively. The deconvoluted images of $\mathrm{N}-\mathrm{GluRI}$ (left) and synaptophysin (right) were shown on the upper panel (similar to a2) whereas the colocalization was shown on the lower panel (similar to a3). (d) The densities of GluRI and synaptophysin clusters were quantified as \# per $100 \mu \mathrm{m}$ of dendrites in neurons that had been treated with fentanyl at concentrations of 0 (control; $n=10), 0.01 \quad(n=10), 0.1(n=11), I(n=1 I)$, and $10(n=10) \mu M$. (e) The proportion of N-GluRI clusters that were colocalized with synaptophysin clusters vs the total number of synaptophysin clusters. ${ }^{*} p<0.05$; ${ }^{*} p<0.01$; ${ }^{* * *} p<0.00$ I, comparing with the control $(0 \mu \mathrm{M})$. 
a
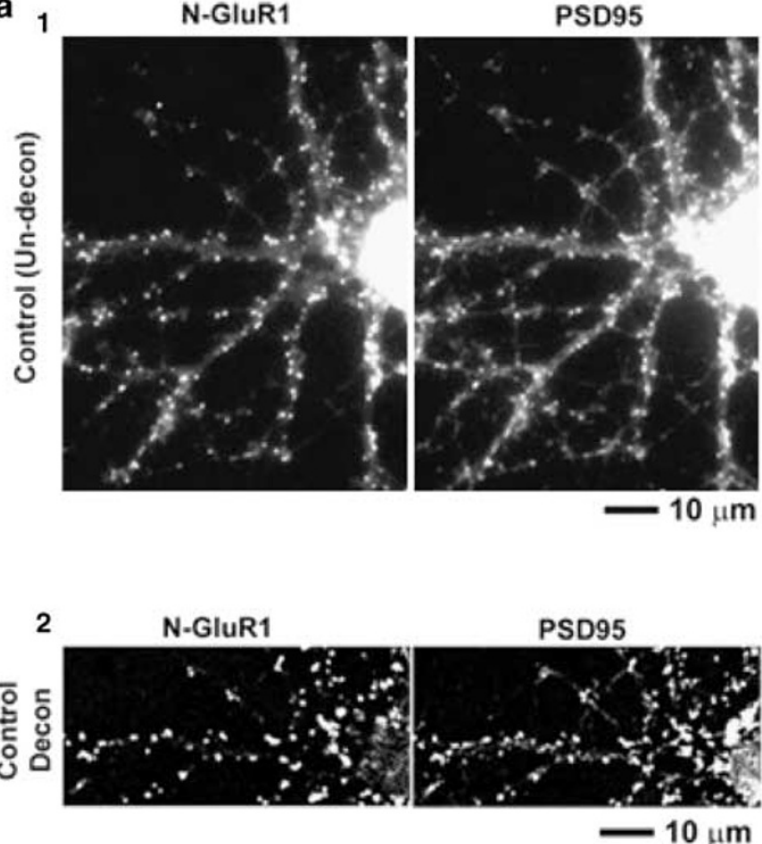

b
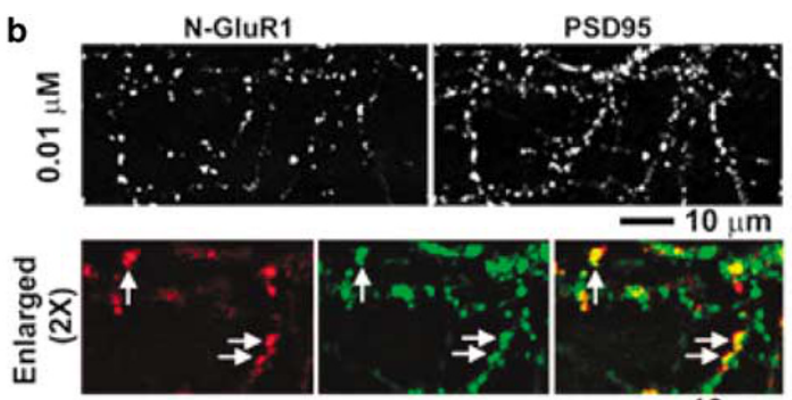

$-10 \mu \mathrm{m}$
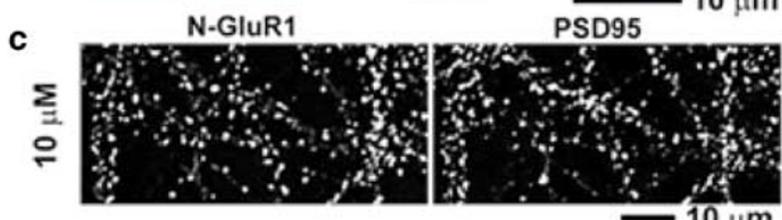

$-10 \mu \mathrm{m}$
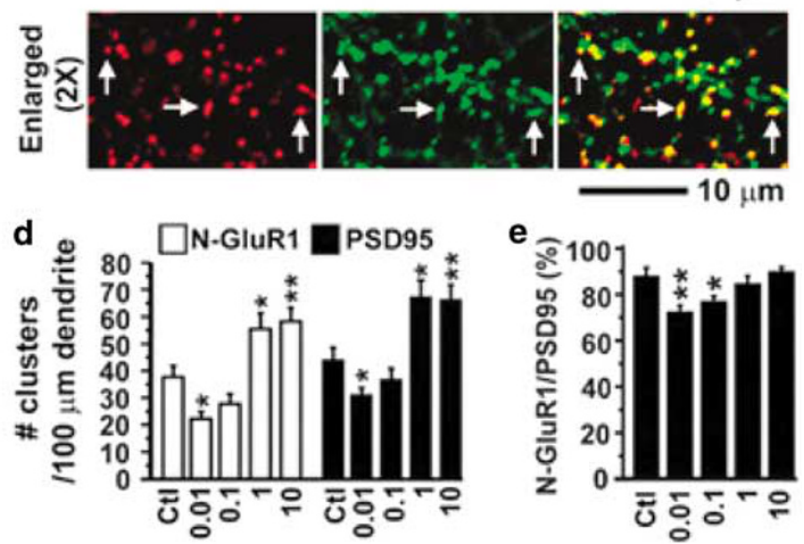

Figure 4 Effects of fentanyl on surface AMPA receptors and PSD95 in low density cultured neurons. (al) An untreated control neuron that was costained with an antibody against the N-terminus of GluRI subunits of AMPA receptors (left, red) and an antibody against a postsynaptic maker PSD95 (right, green). The two images were simple averages of stacks of unprocessed images. (a2) The two images were from the same neuron as in al. They were averages of stacks of images that had been processed by deconvolution analyses using the MetaMorph software with the nearest planes. Note that the clusters were sharper after the deconvolution. (a3) The deconvoluted images of N-GluRI staining (left) and PSD95 staining (middle) were enlarged by two times and pseudocolorized to examine the colocalization (right). ( $b$ and c) Neurons costained with antibodies against N-GluRI and PSD95 that had been treated with fentanyl at low $(0.01 \mu \mathrm{M})$ and high concentrations $(10 \mu \mathrm{M})$, respectively. The deconvoluted images of $\mathrm{N}$-GluRI (left) and PSD95 (right) were shown on the upper panel (similar to a2) whereas the colocalization was shown on the lower panel (similar to a3). (d) The densities of GluRI and PSD95 clusters were quantified as \# per $100 \mu \mathrm{m}$ of dendrites in neurons that had been treated with fentanyl at concentrations of $0($ control; $n=10), 0.01(n=10), 0.1(n=10)$, I $(n=\mid \mathrm{I})$, and $\mathrm{IO}(n=12) \mu \mathrm{M}$. (e) The proportion of $\mathrm{N}$-GluRI clusters that were colocalized with PSD95 clusters vs the total number of PSD95 clusters. * $p<0.05$; ** $p<0.01$; **** $p<0.001$, comparing with the control $(0 \mu \mathrm{M})$

changed the density of PSD95 clusters (Figure 4d, black bars). As PSD95 proteins were strongly enriched in the postsynaptic membrane of glutamatergic synapses (Kennedy, 2000), most of these PSD95 clusters were probably dendritic spines. As previously shown in Figure 1, fentanyl had bidirectional effects on the density of dendritic spines. Therefore, consistent with changes in spines, fentanyl at a low concentration $(0.01 \mu \mathrm{M})$ significantly decreased the density of PSD95 clusters whereas fentanyl at high concentrations ( 1 and $10 \mu \mathrm{M})$ had opposite effects (Figure 4d, right black bars). Furthermore, fentanyl at low concentrations $(0.01$ and $0.1 \mu \mathrm{M})$ changed the proportion of PSD95 clusters that were colocalized with GluR1 clusters $v s$ total number of PSD95 clusters (Figure 4e), confirming that fentanyl can alter AMPA receptor trafficking in excitatory synapses. The combined results in Figures 3 and 4 indicate that chronic treatment with fentanyl can alter the function of excitatory synapses by at least two ways: (1) changing the density of dendritic spines; and (2) changing the amount of postsynaptic AMPA receptors per synapse.
Fentanyl can Cause Persistent and Robust Internalization of MORs at a High Concentration but Little Internalization at a Low Concentration

To investigate the effects of fentanyl on MOR endocytosis in hippocampal neurons, neurons were transfected with plasmids encoding MOR with a $\mathrm{HA}$ tag in the $\mathrm{N}$-terminus (extracellular, labeled as red by antibodies) and a GFP tag in the C-terminus (green, label both intracellular and extracellular receptors; Figure 5). The ratio of red $v s$ green fluorescence was used as an index to quantify the proportion of surface MORs $v s$ total amount of MORs and a decrease of this ratio would indicate endocytosis (Figure 5f). In control-untreated neurons, MORs were brightly stained on the surface (middle panels, Anti-HA; Figure $5 \mathrm{a}$ and $\mathrm{b}$ ) and clustered on the surface of dendritic spines (see arrows in Figure $5 \mathrm{a}$ and $\mathrm{b}$ ). Treatment with fentanyl at low concentrations $(0.01$ and $0.1 \mu \mathrm{M})$ caused no significant internalization of MORs (Figure $5 c$ for an example; Figure 5f; $p>0.05, n=10$ in each group) and did 




Figure 5 The effect of fentanyl on the internalization of MORs was concentration dependent. (a) An untreated control neuron expressing HA-MOR-GFP (green, left) was stained with an anti-HA antibody (red, middle). Right, overlay. In HA-MOR-GFP, an HA tag was fused to the N-terminus (should be on cell surface) and a GFP tag was fused to the C-terminus (emitting green fluorescence all the time). (b) Enlarged images from (a). Arrows denote clustering of MORs on the surface of dendritic spines. (c-e) Similar neurons treated with fentanyl at different concentrations for $2 \mathrm{~h}$ ( $\mathrm{l} \mathrm{h}$ with fentanyl, another with fentanyl + anti- $\mathrm{H}$ antibody). Arrows denote clustering of MORs. Triangles denote MORs aggregating in dendrites after internalization. ( $f$ ) The proportion of red fluorescence vs green fluorescence was used to quantify the ratio of surface vs total MORs in neurons that had been treated with fentanyl at 0 (control), $0.01,0.1, I$, and $10 \mu \mathrm{M}$ ( $n=10$ in each group). (g) The number of MOR-containing dendritic spines per $100 \mu \mathrm{m}$ dendrites. $* p<0.05$; $* * * 0.01$; **** $p<0.00$ I, comparing with the control.

not remove MORs from dendritic spines (Figure $5 \mathrm{~g}$ ). In contrast, treatment with fentanyl at high concentrations ( 1 and $10 \mu \mathrm{M})$ caused significant internalization of MORs (Figure $5 \mathrm{~d}-\mathrm{f}$ ) and removed MORs from dendritic spines (Figure $5 \mathrm{~g}$ ). Whenever the ratio of red/green fluorescence was decreased, fentanyl-induced endocytosis also caused aggregation of MORs in the middle of dendrites (see triangles in Figure 5d and e).
The aggregation of MORs has widely been used to reflect the internalization of MORs in previous studies (Sternini et al, 1996; Haberstock-Debic et al, 2003, 2005). We used this phenomenon as a tool to examine the temporal dynamics of receptor internalization in live neurons expressing MOR-GFP (Figure 6). Normalized coefficient of variation (CV) of green fluorescence was used to quantify the aggregation of MOR in dendrites, which should reflect 
the degree of receptor internalization (see Image Analysis in Materials and Methods). Time-lapse images were taken on the dendrites of neurons expressing MOR-GFPs before, $1 \mathrm{~h}$ and 1 day after the application of fentanyl at concentrations of 0 (control), $0.01,0.1,1$, and $10 \mu \mathrm{M}$ (Figure 6a-e). In untreated control neurons, MORs were mostly smoothly distributed along dendrites (Figure 6a) and no significant change occurred in normalized $\mathrm{CV}$ during the entire observation period (Figure $6 f ; p>0.05, n=8$ ). Fentanyl at $0.01 \mu \mathrm{M}$ did not induce obvious aggregation of MORs (Figure 6b) and caused no significant change in $\mathrm{CV}$ (Figure 6f; $p>0.05, n=8$ ). After the concentration was increased to $0.1 \mu \mathrm{M}$, fentanyl caused MORs to aggregate in dendrites after $1 \mathrm{~h}$ exposure (Figure $6 \mathrm{c}$ and f; $p<0.05$, $n=8)$. However, most of these aggregates had disappeared after 1 day, suggesting that most of the internalized and aggregated MORs might have been reinserted into the cell surface (Figure $6 \mathrm{~d}$ and $\mathrm{f}$ ). In contrast, fentanyl at high concentrations $(1$ or $10 \mu \mathrm{M})$ induced persistent aggregation of MORs in dendrites, which lasted more than 1 day (Figure $6 \mathrm{e}$ and $\mathrm{f} ; n=8)$. These results indicate that fentanyl at high concentrations can induce prolonged internalization of MORs and block the MOR-mediated signaling pathway by removing MORs from the cell surface. In our previous
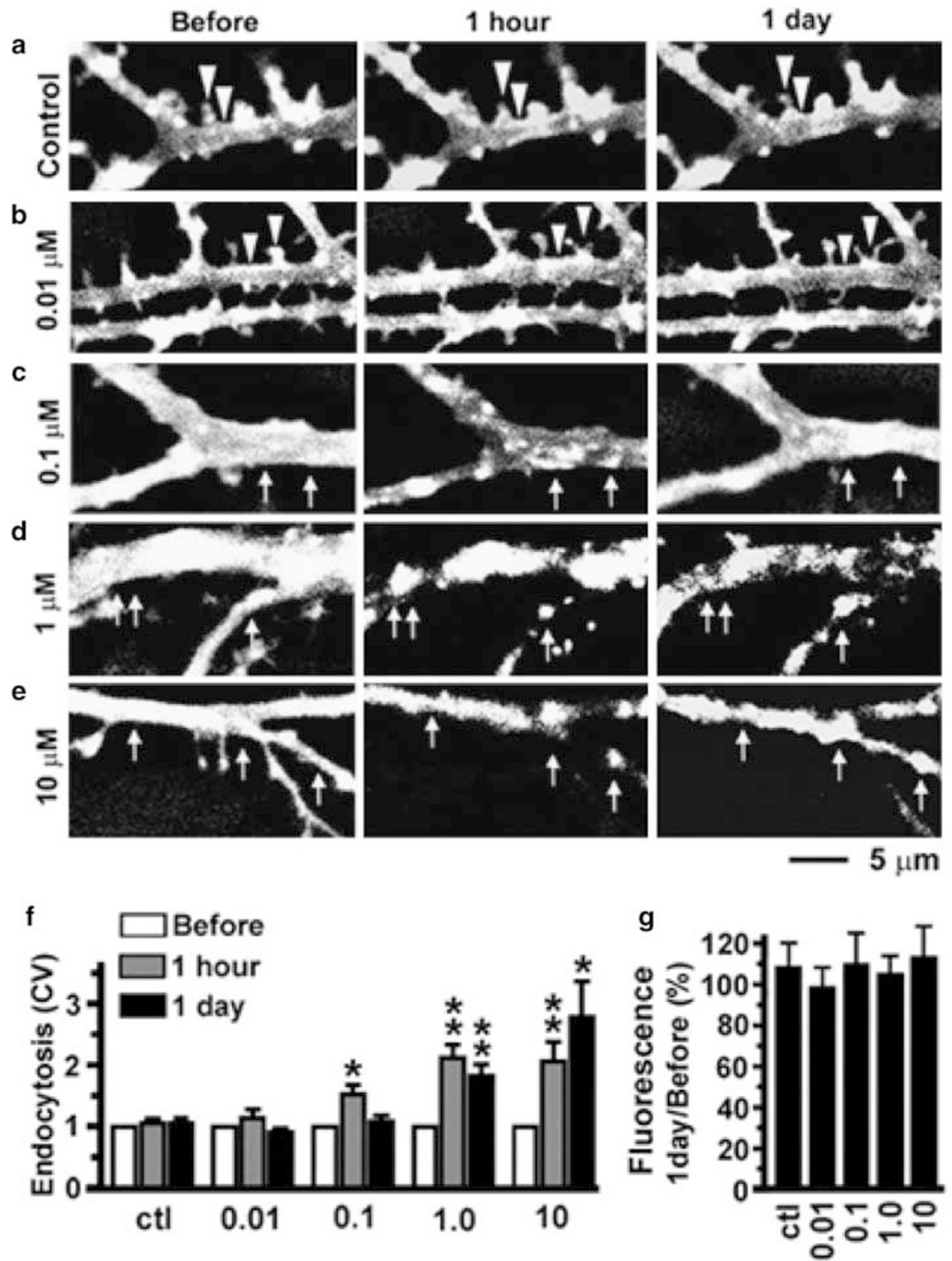

Figure 6 The temporal dynamics of fentanyl-induced MOR internalization was concentration dependent. (a) No obvious aggregation of MORs occurred in an untreated control neuron expressing MOR-GFP. (b-e) Neurons were photographed before and I h and I day after the application of fentanyl at various concentrations ( $0.01,0.1, I$, and $10 \mu \mathrm{M} ; n=8$ neurons in each group). Triangles: MORs were clustered in spines and concentrated on the cell surface in the untreated control (a) and neurons treated with fentanyl at $0.01 \mu \mathrm{M}$ (b). Arrows in (c-e) denote that fentanyl at higher concentrations $(0.1$, I, and $10 \mu \mathrm{M})$ caused aggregation of MORs. (f) Coefficient of variation ( $\mathrm{CV}=$ standard deviation/mean) was used to quantify the aggregation of MORs after endocytosis and changes in CV were normalized by the value before treatment. $(\mathrm{g})$ The ratios of fluorescence intensity after I day of fentanyl treatment vs that before treatment show little degradation of MORs. $* p<0.05$; $* * p<0.01$; $* * * p<0.00$ I, comparing with before. 
studies, the peptide MOR agonist DAMGO caused robust internalization of MORs and most of the internalized MORs were degraded after 1 day of DAMGO treatment (Liao et al, 2007b). Unlike DAMGO, prolonged treatment with fentanyl did not significantly alter the overall fluorescence of the dendrites in neurons expressing MOR-GFP (Figure 6g), suggesting that fentanyl and DAMGO might induce endocytosis of MORs via two distinctly different pathways.
Blockade of Receptor Internalization Prevents the Fentanyl-Induced Bidirectional Changes

Based on previous data in Figures 1-6, we proposed the hypothesis that fentanyl at high concentrations increase the density of dendritic spines by blocking the MOR-mediated signaling pathway via receptor internalization. To test this hypothesis, we used a dominant-negative Dynamin I

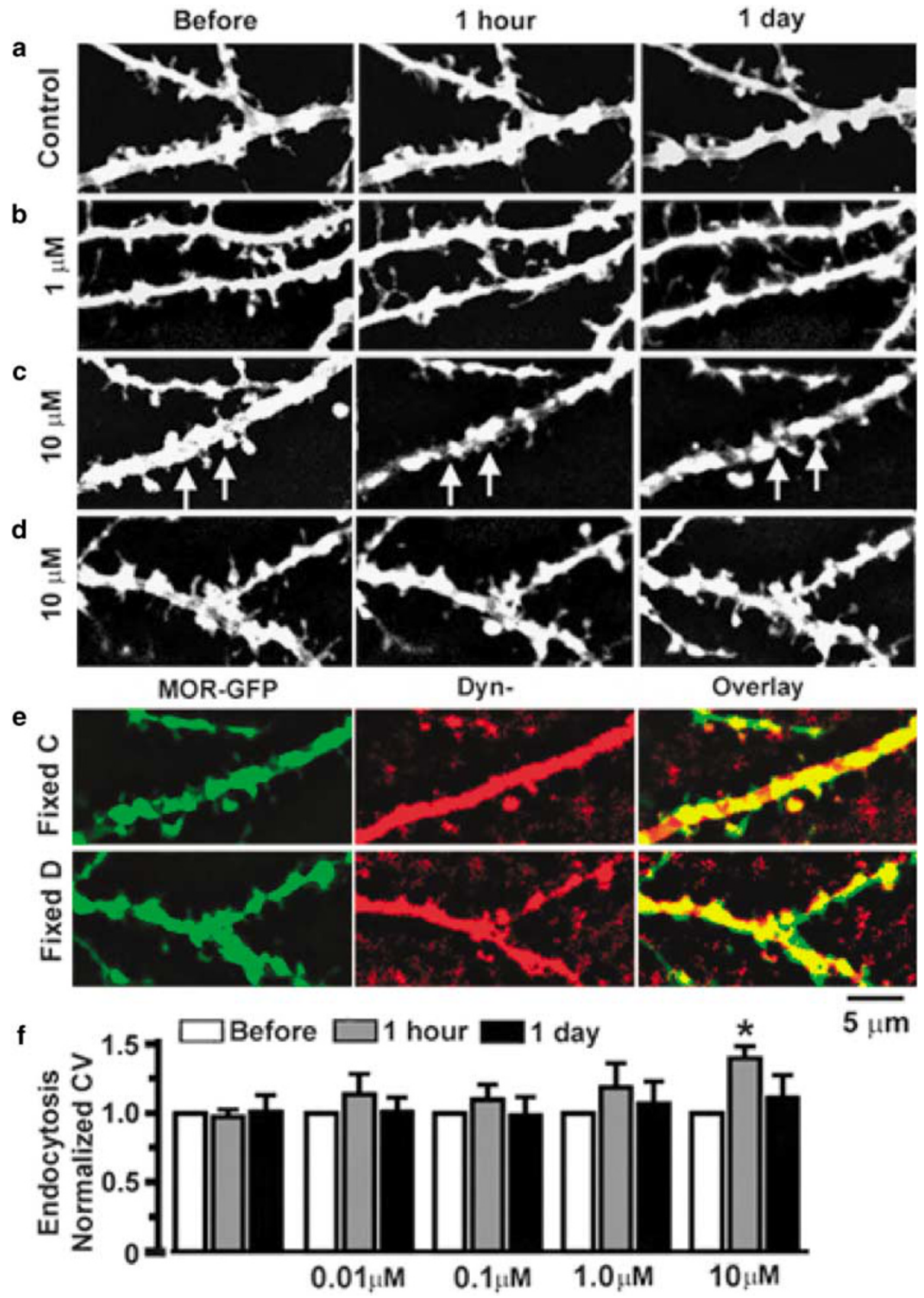

Figure 7 The expression of dominant-negative Dynamin I blocked the internalization of MORs. (a) Neurons were cotransfected with MOR-GFP and HAtagged dominant-negative Dynamin I (K44E). No obvious aggregation of MORs occurred in an untreated control neuron. (b) No obvious aggregation of MORs was found in a neuron that was treated with fentanyl at I $\mu$ M. (c) An example showing that fentanyl at I $\mu \mu M$ could induce MOR aggregation even in the presence of Dynamin I K44E (see Arrows). (d) Another example showing that Dynamin I K44E blocks the effect of fentanyl at I0 $\mu \mathrm{M}$, a result that is opposite to (c). (e) The staining of an anti-HA antibody (red, middle) confirmed that the two neurons in (c) and (d) indeed expressed HA-tagged Dynamin I K44E (left, middle, and right: GFP, HA, and overlay). ( $f$ Coefficient of variation ( $C V=$ standard deviation/mean) was used to quantify the aggregation of MORs after endocytosis and changes in CV were normalized by the value before treatment. $n=8$ in each group $(0,0.01,0.1,1$, and $10 \mu \mathrm{M})$; * $p<0.05$; *** $<0.0$ I; **** $<0.00$ I, comparing with before. 
(the K44E mutant, referred to as Dyn-; see Chu et al, 1997) to block the dynamin-mediated internalization of MORs (Figure 7). High density cultured neurons (at 21 DIV) that had been cotransfected with the K44E Dynamin I mutant and MOR-GFP were treated with fentanyl at concentrations of $0,0.01,0.1,1$, and $10 \mu \mathrm{M}$. In contrast to neurons without the K44E Dynamin I mutant (see Figure 6 for comparison), treatment with fentanyl at $1 \mu \mathrm{M}$ no longer caused obvious MOR aggregation and had no significant effect on the CV of MOR-GFP fluorescence in dendrites of neurons expressing this mutant (Figure $7 \mathrm{~b}$ and $\mathrm{f} ; p>0.05, n=8)$. However, the expression of dominant-negative Dynamin I could not completely block the internalization of MORs when the concentration of fentanyl reached as high as $10 \mu \mathrm{M}$ (Figure $7 \mathrm{c}$ and $\mathrm{d}$ for two different examples; Figure $7 \mathrm{f}$ for quantification; $p<0.05$ at $1 \mathrm{~h}, n=8)$. At such a high concentration $(10 \mu \mathrm{M})$, fentanyl could still cause aggregation of MORs in five out of eight neurons and all of these eight neurons clearly expressed K44E Dynamin I proteins (Figure 7e). These results suggest that fentanyl might be able to induce the internalization of MORs via other dynamin independent pathways if the concentration is very high $(>10 \mu \mathrm{M})$.

To further test the hypothesis that fentanyl at high concentrations increases the density of dendritic spines by blocking the MOR-mediated signaling pathway via receptor internalization, high-density cultured neurons that expressed K44E Dynamin I mutant and GFP were treated with fentanyl at concentrations of $0,0.01,0.1,1$, and $10 \mu \mathrm{M}(n=17$ in the group treated with fentanyl at $10 \mu \mathrm{M} ; n=10-12$ in all other groups). Similar to neurons without the transfection of K44E Dynamin I mutant (see Figure 1 for comparison), treatment with fentanyl at a low concentration $(0.01 \mu \mathrm{M})$ caused collapse of dendritic spines (Figure 8b) and fentanyl at 0.01 and $0.1 \mu \mathrm{M}$ significantly decreased the density of protrusions and spines after 1-3 days of treatment (Figure $8 \mathrm{f}$ and $\mathrm{g}$ ). In contrast to neurons without the transfection of $\mathrm{K} 44 \mathrm{E}$ Dynamin I mutant, treatment with fentanyl at high concentrations ( 1 and $10 \mu \mathrm{M}$ ) no longer induced the emergence of new dendritic protrusions and spines in neurons expressing this mutant (Figure $8 \mathrm{f}$ and $\mathrm{g}$ ). On the contrary, fentanyl at $1 \mu \mathrm{M}$ caused collapse of spines (Figure 8c) and significantly decreased the density of dendritic protrusions and spines (Figure $8 \mathrm{f}$ and $\mathrm{g}$ ). The effects of fentanyl on dendritic spines became very variable when the concentration of fentanyl reached as high as $10 \mu \mathrm{M}$ (Figure 8f and g). At such a high concentration $(10 \mu \mathrm{M})$, fentanyl decreased the density of spines in 9 out of 17 neurons and increased this density in 8 out of 17 neurons. Due to this mixed result, no significant change was found after the treatment ( $p>0.05$; last 3 bars in Figure $8 \mathrm{f}$ and g). This mixed result caused by fentanyl at a very high concentration $(>10 \mu \mathrm{M})$ might be due to incomplete blockade of the internalization of MORs by K44E Dynamin I (see Figure $7 \mathrm{f}$ ) or a nonspecific effect via a MOR independent pathway. Experiments using neurons expressing K44E Dynamin I proteins (Figures 7 and 8) support the hypothesis that the concentration-dependent bidirectional effects of fentanyl on dendritic spines rely on the internalization of MORs.

\section{DISCUSSION}

Morphine, oxycodone, methadone, and fentanyl are among the most commonly prescribed opioids for pain management (Hanks and Reid, 2005). Fentanyl is frequently used as an opioid analgesic in surgery (Stanley, 2005) and often used to treat chronic cancer and noncancer pains (Skaer, 2006; Trescot et al, 2008). Furthermore, addiction to fentanyl has emerged as a major issue due to the marked increase in the number of abusers in the past decade and the propensity of opiate addicts to mix fentanyl with heroin and to die from overdose (Compton and Volkow, 2005; Schumann et al, 2008; Kronstrand et al, 1997; Fodale et al, 2008). Due to the extensive use and abuse of fentanyl and potential importance of neural plasticity in addiction, characterizing the effects of this drug on dendritic spines and AMPA receptors should be of great interest to clinicians, neuroscientists, and pharmacologists.

\section{Dose-Dependent Bidirectional Effects of Fentanyl on Dendritic Spines and AMPA Receptors}

This study demonstrates that fentanyl causes dose-dependent bidirectional changes in dendritic spines and AMPA receptors (Figures 1, 3 and 4). These bidirectional changes were blocked by the selective MOR antagonist CTOP, indicating that fentanyl-induced changes in dendritic spines are mainly mediated via MORs (Figure 2). This biphasic response stands in contrast to the previous studies showing that chronic treatment with morphine, which induces little internalization of MORs, caused collapse of dendritic spines and decreased the amplitude and frequency of miniature excitatory synaptic currents (mEPSCs; Liao et al, 2005, $2007 a, b)$. The decrease in mEPSC frequency was probably due to the collapse of spines whereas the decrease in mEPSC amplitude was probably due to the removal of synaptic AMPA receptors (Liao et al, 2007a). In contrast, opioids such as DAMGO and etorphine, which induced robust internalization of MORs, increased the density of dendritic spines and the frequency of mEPSCs, causing effects that are opposite to those of morphine (Liao et al, 2005, 2007a, b). In this study, we found that the same opioid drug could cause opposite effects on dendritic spines if different concentrations were applied. Fentanyl at different concentrations induced bidirectional changes on the density of dendritic spines and synaptic AMPA receptors (Figures 1-4). At low concentrations $(0.01$ and $0.1 \mu \mathrm{M})$, chronic treatment with fentanyl caused collapse of preexisting dendritic spines whereas, high concentrations ( 1 and $10 \mu \mathrm{M})$ induced the emergence of new dendritic spines (Figure 1). Furthermore, fentanyl at a low concentration $(0.01 \mu \mathrm{M})$ caused the removal of AMPA receptors from synapses whereas fentanyl at high concentrations ( 1 and $10 \mu \mathrm{M})$ increased the number of synapses that contained AMPA receptors (Figures 3 and 4). Chronic treatment with morphine decreases the density of dendritic spines and the amount of synaptic AMPA receptors in hippocampal neurons (Liao et al, 2005). In contrast, chronic morphine administration increases the amount of GluR1 subunits of AMPA receptors in the VTA (Lane et al, 2008). It will be interesting to further investigate the cellular mechanism underlying the differential effects of chronic opioid exposure on different parts of the brain. 

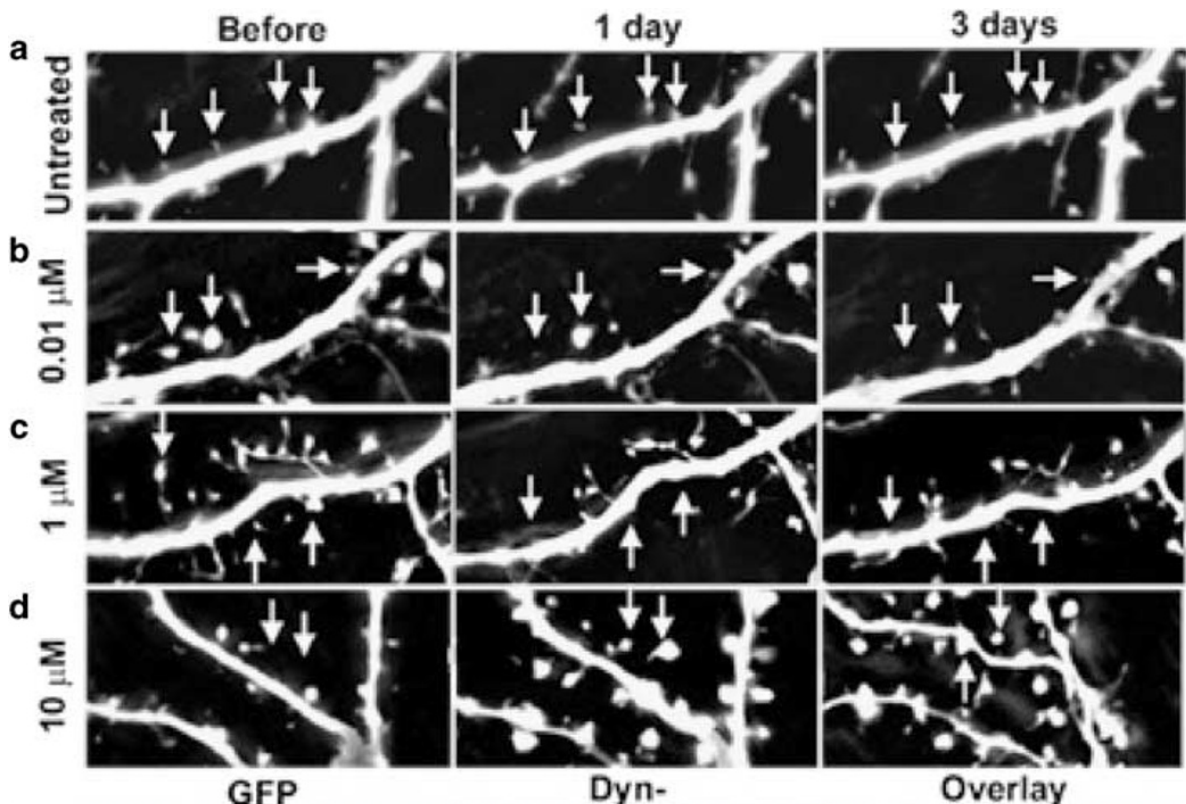

e
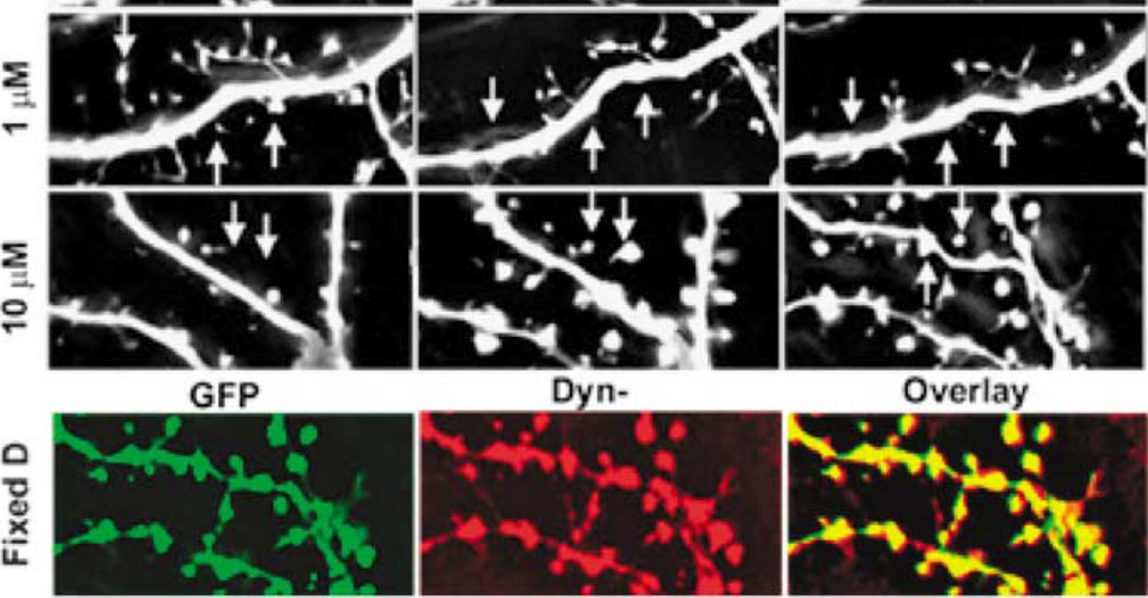

d
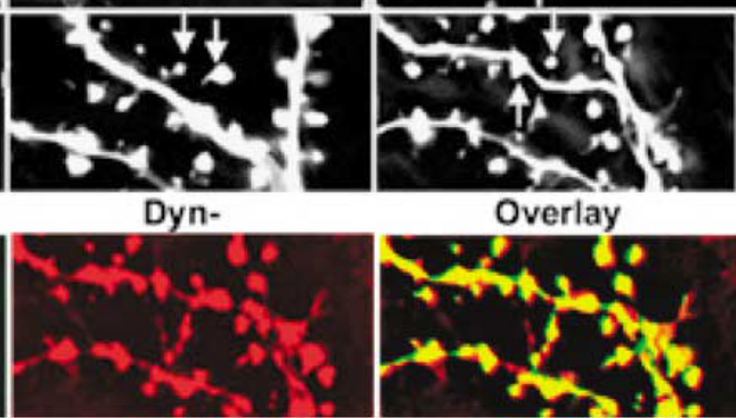

Overlay

f

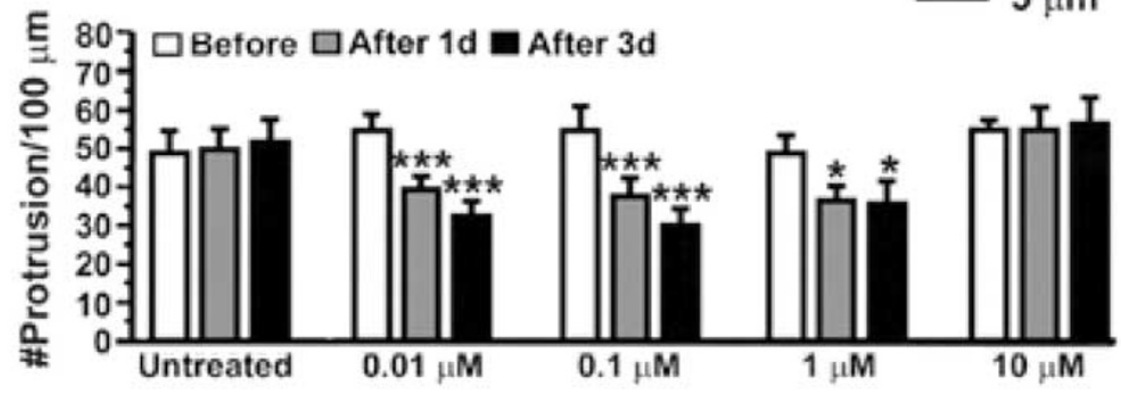

g

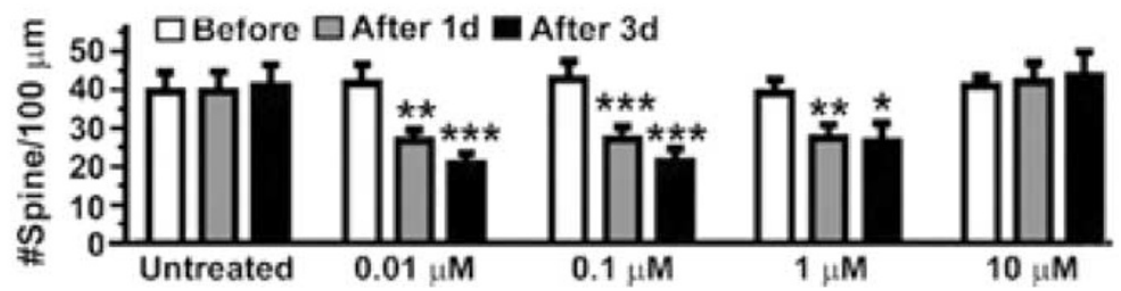

Figure 8 The blockade of MOR internalization reversed the effect of fentanyl at high concentrations. (a) Neurons were cotransfected with GFP and HAtagged Dynamin I K44E. No obvious change in the density of spines was found in untreated control neurons (arrows). (b and c) Fentanyl at concentrations of $<I \mu M$ caused collapse of spines (arrows). (d) An example shows that fentanyl at a very high concentration $(>10 \mu \mathrm{M})$ can induce the emergence of new spines. In 8 of 17 neurons, fentanyl at $10 \mu \mathrm{M}$ increased the density of spines. (e) The same neuron as in (d). The presence of Dyn- in the GFP-expressing neuron (green, left) was confirmed by an anti-HA antibody (middle). Right, overlay. ( $\mathrm{f}$ and $\mathrm{g}$ ) The densities of dendritic protrusions and spines (\# per I00 $\mu \mathrm{m}$ of dendrites) were quantified in neurons that had been treated with fentanyl at $0(n=\mid 2), 0.0|(n=\mid 0), 0|.(n=||), \mid(n=\mid 0)$, and $\mid 0(n=\mid 7) \mu M$ for $\mid-$ 3 days. The sample size in the group using fentanyl at I $0 \mu \mathrm{M}$ was almost doubled due to mixed results (see main text). Note that the effects of fentanyl at I and $10 \mu \mathrm{M}$ in neurons expressing GFP and Dynamin I K44E are different from those in neurons expressing GFP alone (see Figure I for a comparison), * $p<0.05$; $* * 0.01$; **** $p<0.00$ I, comparing with before.

Relationship Between Fentanyl-Induced Changes in Spines and Cognitive Dysfunctions

Chronic exposure to MOR agonists heroin, morphine, and methadone lead to many cognition dysfunctions including deficits in spatial learning and memory (Bodnar and Hadjimarkou, 2003; Gruber et al, 2007). In contrast, MOR antagonists such as naloxone and naltrexone enhance learning and memory and block the adverse cognitive effects of electroconvulsive therapy (ECT; Canli et al, 1990; Gallagher et al, 1985; Prudic et al, 1999). In mice overexpressing human amyloid precursor protein (hAPP; a model of preclinical Alzheimer's disease), the expression level of enkephalin is increased and memory deficits are reduced by $\beta$-funaltrexamine, an irreversible blocker of MORs (Meilandt et al, 2008). Morphine significantly 

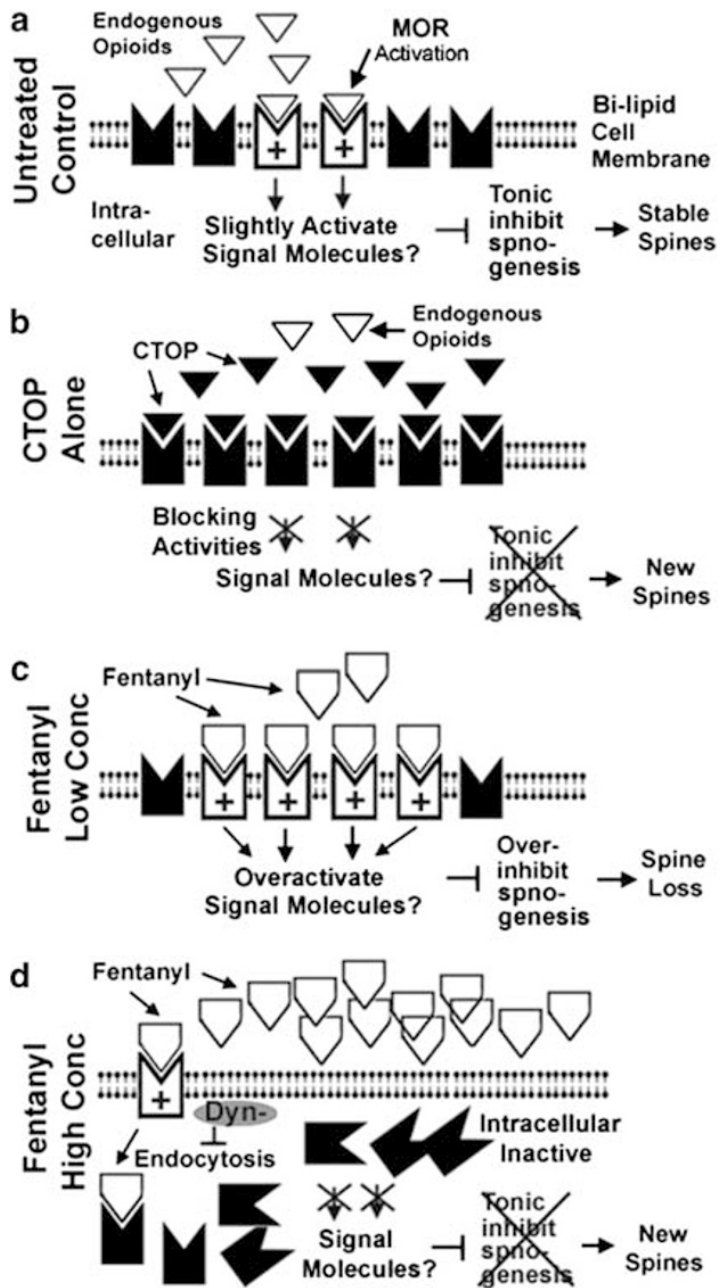

Figure 9 A hypothetical model summarizing the relationship between the internalization of MORs and fentanyl-induced dose-dependent bidirectional changes in dendritic spines. (a) In untreated control neurons, a low level of continuing MOR activation stabilizes the density of dendritic spines via tonic inhibition of spinogenesis (formation of new spines). The signaling molecules are yet unknown. The tonic inhibition of spinogenesis might either result from the binding of endogenous opioids and/or the constitutive activities of MORs. (b) CTOP induces emergence of new dendritic spines by removing the MOR-mediated tonic inhibition of spinogenesis. (c) Fentanyl at low concentrations $(0.0 \mathrm{I}-0.1 \mu \mathrm{M})$ induces strong and prolonged activation of MORs, causing loss of spines by overinhibiting spinogenesis or by destabilizing preexisting spines. (d) Fentanyl at high concentrations $(1-10 \mu \mathrm{M})$ removes MORs from the cell surface via endocytosis. Therefore, the MOR-mediated tonic inhibition of spinogenesis is disabled, leading to the emergence of new dendritic spines. The gray oval symbol denotes that the expression of dominant-negative dynamin (Dyn-) blocks the internalization of MORs. This blockade would allow continuing activation of MORs by fentanyl. Under this blockade, fentanyl at a high concentration $(>\mid \mu \mathrm{M})$ can cause spine loss.

decreases the density of dendritic spines whereas MOR antagonist naloxone has an opposite effect (Liao et al, 2005). Therefore, it is tempting to use the severity of opioidinduced collapse of dendritic spines to speculate on the likelihood for a specific opioid to cause cognitive deficits. Fentanyl at $0.01 \mu \mathrm{M}$ decreased the density of spines by $36 \%$ (Figure 1), which is similar to the effect of morphine (decreased by 35\%; Liao et al, 2005). However, fentanyl decreased the density of spines by $24 \%$ at $0.1 \mu \mathrm{M}$ and started to increase the density of spines at $1 \mu \mathrm{M}$ (Figure 1 ). Therefore, at a concentration ranging from 0.01 to $1 \mu \mathrm{M}$, fentanyl is likely to cause far less damage to dendritic spines than morphine. Although it is difficult to know the concentration of fentanyl in the brain during various clinical applications, the unique bidirectional effects of fentanyl on dendritic spines probably contribute to the cellular basis of an interesting clinical puzzle: Treatment of chronic pain with fentanyl caused fewer incidents of cognitive deficits than treatment with morphine in elderly patients (McNamara, 2002). In another clinical puzzle, anesthesiologists were surprised that high-dose fentanyl caused significantly fewer incidents of postoperative cognitive dysfunction than low dose (Silbert et al, 2006). Based on this study, fentanyl at a high concentration might be able to protect dendritic spines during anesthesia, providing a plausible explanation for the second puzzle.

\section{The Effects of Fentanyl on the Internalization of MORs}

This study demonstrates that the ability of fentanyl to induce receptor internalization is concentration dependent (Figures 5 and 6). Fentanyl is one of the most potent opioid agonists used in clinic; it is a synthetic opioid in the phenylpiperidine series with a chemical structure different from morphine (Cometta-Morini et al, 1992; Rang et al, 1995). It is believed that fentanyl has a very high affinity for MORs, mediates very strong transduction downstream from the ligand-receptor complex, occupies a small number of binding sites and induces 'weak' internalization of opioid receptors (Martini and Whistler, 2007). This study reveals that fentanyl can induce 'strong' internalization of MORs if high concentrations are applied $(1-10 \mu \mathrm{M})$ whereas it induces 'weak' internalization if low concentrations are applied $(0.01-0.1 \mu \mathrm{M})$.

This study demonstrates that the RAVE (relative activity $v s$ endocytosis) value of a specific opioid can be changed if different concentrations are applied. Morphine induces little receptor internalization in most cell types, whereas other opioids such as DAMGO, etorphine, and methadone cause strong receptor internalization (Alvarez et al, 2002; Sternini et al, 1996; Whistler and von Zastrow, 1998). A 'RAVE' hypothesis has been proposed to explain the roles of receptor internalization and desensitization in opioid addiction and tolerance (Finn and Whistler, 2001; He et al, 2002; Whistler et al, 1999). According to this hypothesis, chronic treatment with an opioid drug with a high RAVE value would cause more severe tolerance and addiction (Alvarez et al, 2001). Fentanyl was previously proposed to have high RAVE value and thus high addictive liability (Martini and Whistler, 2007). This study indicates that the RAVE value of fentanyl can be 'high' or 'low' depending on concentrations applied. Fentanyl at a low concentration $(0.01 \mu \mathrm{M})$ causes strong collapse of spines but induces no significant receptor internalization, yielding a high RAVE value. Fentanyl at a high concentration $(10 \mu \mathrm{M})$ causes no collapse of spines (actually has the opposite effects) but induces robust receptor internalization, yielding a low RAVE value. 


\section{Relationship Between Receptor Internalization and Spine Changes}

K44E mutant of Dynamin I is a dominant-negative inhibitor that can block the internalization of mu, delta, and kappa opioid receptors (Zhao et al, 2006; Chu et al, 1997). The blockade of receptor internalization by dominant-negative Dynamin I (K44E) reversed the effects of fentanyl at high concentrations ( 1 and $10 \mu \mathrm{M})$ on dendritic spines, preventing the bidirectional effects of fentanyl (Figures 7 and 8). These results indicate that the bidirectional changes induced by fentanyl are mainly caused by fentanyl-induced MOR internalization at high concentrations. However, the possibility that Dynamin I (K44E) might affect a cellular mechanism that is independent of MOR internalization cannot be excluded. As summarized in our model (Figure 9), this study provides a direct mechanistic link between the internalization of MOR and fentanyl-induced plasticity of dendritic spines, which might play important roles in drug addiction and cognition dysfunctions. An ideal opioid drug with minimal side effects should have properties that are similar to those of endogenous opioid peptides: strong signal transduction and robust endocytosis (Martini and Whistler, 2007). It is conceivable that a novel opioid with 'ideal' properties might aim to shift the bidirectional effects toward a lower concentration in the future.

\section{Summary}

This study demonstrates that chronic treatment with fentanyl at low concentrations causes the collapse of dendritic spines and removal of synaptic AMPA receptors, whereas fentanyl at high concentrations has opposite effects. This bidirectional effect is prevented by the blockade of MOR internalization via the expression of a dominant-negative Dynamin I (K44E), indicating an important role of receptor internalization in this cellular process. Characterizing the fentanyl-induced alterations in dendritic spines and AMPA receptor trafficking might shed new light on the cellular mechanism underlying the addiction, tolerance, and cognitive deficits that are caused by the illicit abuse and/or clinical use of this drug.

\section{ACKNOWLEDGEMENTS}

We thank Dr George Wilcox and Dr Brian Hoover for their helpful comments, and Mr Eric Nordstrom for his technical support. This study is supported by National Institute for Drug Abuse (NIDA) grants R01-DA020582 and K02DA025048 to DL; grants from Chinese government (30570591 and 06MA147) to HL; and NIDA grants P50DA011806, R01-DA007339, R01-DA000564, R01-DA016674, K05-DA070554, and K05-DA000513 to HHL and PYL.

\section{DISCLOSURE/CONFLICT OF INTEREST}

The author(s) declare that, except for income received from my primary employer, no financial support or compensation has been received from any individual or corporate entity over the past 3 years for research or professional service and there are no personal financial holdings that could be perceived as constituting a potential conflict of interest.

\section{REFERENCES}

Alvarez V, Arttamangkul S, Williams JT (2001). A RAVE about opioid withdrawal. Neuron 32: 761-763.

Alvarez VA, Arttamangkul S, Dang V, Salem A, Whistler JL, von Zastrow $\mathrm{M}$ et al (2002). $\mu$-Opioid receptors: ligand-dependent activation of potassium conductance, desensitization, and internalization. J Neurosci 22: 5769-5776.

Arvidsson U, Riedl M, Chakrabarti S, Lee JH, Nakano AH, Dado RJ et al (1995). Distribution and targeting of a mu-opioid receptor (MOR1) in brain and spinal cord. J Neurosci 15: 3328-3341.

Biala G, Betancur C, Mansuy IM, Giros B (2005). The reinforcing effects of chronic D-amphetamine and morphine are impaired in a line of memory-deficient mice overexpressing calcineurin. Eur J Neurosci 21: 3089-3096.

Bliss TV, Collingridge GL (1993). A synaptic model of memory: long-term potentiation in the hippocampus. Nature 361: 31-39.

Bodnar RJ (2007). Endogenous opiates and behavior: 2006. Peptides 28: 2435-2513.

Bodnar RJ, Hadjimarkou MM (2003). Endogenous opiates and behavior: 2002. Peptides 24: 1241-1302.

Canli T, Cook RG, Miczek KA (1990). Opiate antagonists enhance the working memory of rats in the radial maze. Pharmacol Biochem Behav 36: 521-525.

Chu P, Murray S, Lissin D, von Zastrow M (1997). Delta and kappa opioid receptors are differentially regulated by dynamindependent endocytosis when activated by the same alkaloid agonist. J Biol Chem 272: 27124-27130.

Cometta-Morini C, Maguire PA, Loew GH (1992). Molecular determinants of $\mathrm{mu}$ receptor recognition for the fentanyl class of compounds. Mol Pharmacol 41: 185-196.

Compton WM, Volkow ND (2005). Major increases in opioid analgesic abuse in the United States: concerns and strategies. Drug Alcohol Depend 81: 103-107.

Ersche KD, Clark L, London M, Robbins TW, Sahakian BJ (2006). Profile of executive and memory function associated with amphetamine and opiate dependence. Neuropsychopharmacology 31: 1036-1047.

Fan GH, Wang LZ, Qiu HC, Ma L, Pei G (1999). Inhibition of calcium/calmodulin-dependent protein kinase II in rat hippocampus attenuates morphine tolerance and dependence. Mol Pharmacol 56: 39-45.

Finn AK, Whistler JL (2001). Endocytosis of the mu opioid receptor reduces tolerance and a cellular hallmark of opiate withdrawal. Neuron 32: 829-839.

Fodale V, Mafrica F, Santamaria LB, Coleman JJ (2008). Killer fentanyl: is the fear justified? Expert Opin Drug Saf 7: 213-217.

Gallagher M, Bostock E, King R (1985). Effects of opiate antagonists on spatial memory in young and aged rats. Behav Neural Biol 44: 374-385.

Goslin K, Banker Gin (1991). In: Banker G, Goslin K (eds). Culturing Nerve Cells. MIT Press: London. pp 251-283.

Gruber SA, Silveri MM, Yurgelun-Todd DA (2007). Neuropsychological consequences of opiate use. Neuropsychol Rev 17: 299-315.

Haberstock-Debic H, Kim KA, Yu YJ, von Zastrow M (2005). Morphine promotes rapid, arrestin-dependent endocytosis of $\mu$-opioid receptors in striatal neurons. J Neurosci 25: 7847-7857.

Haberstock-Debic H, Wein M, Barrot M, Colago EE, Rahman Z, Neve RL et al (2003). Morphine acutely regulates opioid receptor trafficking selectively in dendrites of nucleus accumbens neurons. J Neurosci 23: 4324-4332.

Hanks GW, Reid C (2005). Contribution to variability in response to opioids. Support Care Cancer 13: 145-152.

He L, Fong J, von Zastrow M, Whistler JL (2002). Regulation of opioid receptor trafficking and morphine tolerance by receptor oligomerization. Cell 108: 271-282. 
Hollmann M, Heinemann S (1994). Cloned glutamate receptors. Annu Rev Neurosci 17: 31-108.

Kalivas PW, Alesdatter JE (1993). Involvement of N-methyl-Daspartate receptor stimulation in the ventral tegmental area and amygdala in behavioral sensitization to cocaine. J Pharmacol Exp Ther 267: 486-495.

Karler R, Calder LD, Chaudhry IA, Turkanis SA (1989). Blockade of 'reverse tolerance' to cocaine and amphetamine by MK- 801 . Life Sci 45: 599-606.

Kauer JA, Malenka RC (2007). Synaptic plasticity and addiction. Nat Rev Neurosci 8: 844-858.

Kronstrand R, Druid H, Holmgren P, Rajs J (1997). A cluster of fentanyl-related deaths among drug addicts in Sweden. Forensic Sci Int 88: 185-193.

Kelley AE (2004). Memory and addiction: shared neural circuitry and molecular mechanisms. Neuron 44: 161-179.

Kennedy MB (2000). Signal-processing machines at the postsynaptic density. Science 290: 750-754.

Lane DA, Lessard AA, Chan J, Colago EE, Zhou Y, Schlussman SD et al (2008). Region-specific changes in the subcellular distribution of AMPA receptor GluR1 subunit in the rat ventral tegmental area after acute or chronic morphine administration. J Neurosci 28: 9670-9681.

Liao D, Grigoriants OO, Loh HH, Law PY (2007a). Agonistdependent postsynaptic effects of opioids on miniature excitatory postsynaptic currents in cultured hippocampal neurons. J Neurophysiol 97: 1485-1494.

Liao D, Grigoriants OO, Wang W, Wiens K, Loh HH, Law PY (2007b). Distinct effects of individual opioids on the morphology of spines depend upon the internalization of $\mathrm{mu}$ opioid receptors. Mol Cell Neurosci 35: 456-469.

Liao D, Lin H, Law PY, Loh HH (2005). Mu-opioid receptors modulate the stability of dendritic spines. Proc Natl Acad Sci USA 102: 1725-1730.

Liao D, Scannevin RH, Huganir R (2001). Activation of silent synapses by rapid activity-dependent synaptic recruitment of AMPA receptors. J Neurosci 21: 6008-6017.

Liao D, Zhang X, O'Brien R, Ehlers MD, Huganir RL (1999). Regulation of morphological postsynaptic silent synapses in developing hippocampal neurons. Nat Neurosci 2: 37-43.

Lin H, Huganir R, Liao D (2004). Temporal dynamics of NMDA receptor-induced changes in spine morphology and AMPA receptor recruitment to spines. Biochem Biophys Res Commun 316: $501-511$.

Malenka RC (1994). Synaptic plasticity in the hippocampus: LTP and LTD. Cell 78: 535-538.

Malinow R, Mainen ZF, Hayashi Y (2000). LTP mechanisms: from silence to four-lane traffic. Curr Opin Neurobiol 10: 352-357.

Mansour A, Fox CA, Akil H, Watson SJ (1995). Opioid-receptor mRNA expression in the rat CNS: anatomical and functional implications. Trends Neurosci 18: 22-29.

Martin SJ, Grimwood PD, Morris RGM (2000). Synaptic plasticity and memory: an evaluation of the hypothesis. Annu Rev Neurosci 23: 649-711.

Martini L, Whistler JL (2007). The role of mu opioid receptor desensitization and endocytosis in morphine tolerance and dependence. Curr Opin Neurobiol 17: 556-564.

McNamara P (2002). Opioid switching from morphine to transdermal fentanyl for toxicity reduction in palliative care. Palliat Med 16: 425-434.

Meilandt WJ, Yu GQ, Chin J, Roberson ED, Palop JJ, Wu T et al (2008). Enkephalin elevations contribute to neuronal and behavioral impairments in a transgenic mouse model of Alzheimer's disease. J Neurosci 28: 5007-5017.

Mintzer MZ, Copersino ML, Stitzer ML (2005). Opioid abuse and cognitive performance. Drug Alcohol Depend 78: 225-230.
Nestler EJ (2002). Common molecular and cellular substrates of addiction and memory. Neurobiol Learn Mem 78: 637-647.

O'Brien RJ, Kamboj S, Ehlers MD, Rosen KR, Fischbach GD, Huganir RL (1998). Activity-dependent modulation of synaptic AMPA receptor accumulation. Neuron 21: 1067-1078.

Prudic J, Fitzsimons L, Nobler MS, Sackeim HA (1999). Naloxone in the prevention of the adverse cognitive effects of ECT: a within-subject, placebo controlled study. Neuropsychopharmacology 21: 285-293.

Rang HP, Dale MM, Ritter JM, Gardner P (1995). Analgesic Drugs. Chapter 31 Pharmacology 3rd edn. Churchill Livingstone Inc., 609-633 ISBN 0-443-07560-3.

Robinson TE, Gorny G, Savage VR, Kolb B (2002). Widespread but regionally specific effects of experimenter- versus self-administered morphine on dendritic spines in the nucleus accumbens, hippocampus, and neocortex of adult rats. Synapse 46: 271-279.

Schumann H, Erickson T, Thompson TM, Zautcke JL, Denton JS (2008). Fentanyl epidemic in Chicago, Illinois and surrounding Cook County. Clin Toxicol (Phila) 46: 501-506.

Silbert BS, Scott DA, Evered LA, Lewis MS, Kalpokas M, Maruff P et al (2006). A comparison of the effect of high- and low-dose fentanyl on the incidence of postoperative cognitive dysfunction after coronary artery bypass surgery in the elderly. Anesthesiology 104: 1137-1145.

Skaer TL (2004). Practice guidelines for transdermal opioids in malignant pain. Drugs 64: 2629-2638.

Skaer TL (2006). Transdermal opioids for cancer pain. Health Qual Life Outcomes 4: 24.

Stanley TH (1992). The history and development of the fentanyl series. J Pain Symptom Manage 7(3 Suppl): S3-S7.

Stanley TH (2005). Fentanyl. J Pain Symptom Manage 29(5 Suppl): S67-S71.

Sternini C, Spann M, Anton B, Keith Jr DE, Bunnett NW, von Zastrow $\mathrm{M}$ et al (1996). Agonist-selective endocytosis of mu opioid receptor by neurons in vivo. Proc Natl Acad Sci USA 93: 9241-9246.

Trescot AM, Glaser SE, Hansen H, Benyamin R, Patel S, Manchikanti L (2008). Effectiveness of opioids in the treatment of chronic non-cancer pain. Pain Physician 11: S181-S200.

Trujillo KA, Akil H (1991). Inhibition of morphine tolerance and dependence by the NMDA receptor antagonist MK-801. Science 251: 85-87.

Vorel SR, Liu X, Hayes RJ, Spector JA, Gardner EL (2001). Relapse to cocaine-seeking after hippocampal theta burst stimulation. Science 292: 1175-1178.

Whistler JL, Chuang H, Chu P, Jan LY, von Zastrow M (1999). Functional dissociation of $\mu$ opioid receptor signaling and endocytosis: implications for the biology of opiate tolerance and addiction. Neuron 23: 737-746.

Whistler JL, von Zastrow M (1998). Morphine-activated opioid receptors elude desensitization by $\beta$-arrestin. PNAS 95: 9914-9919.

Wiens K, Lin H, Liao D (2005). Rac1 induces the clustering of AMPA receptors during spinogenesis. J Neurosci 25: 10627-10636.

Williams JT, Christie MJ, Manzoni O (2001). Cellular and synaptic adaptations mediating opioid dependence. Physiol Rev 81: 299-343.

Wolf ME (2002). Addiction: making the connection between behavioral changes and neuronal plasticity in specific pathways. Mol Interv 2: 146-157.

Wolf ME, Jeziorski M (1993). Coadministration of MK-801 with amphetamine, cocaine or morphine prevents rather than transiently masks the development of behavioral sensitization. Brain Res 613: 291-294.

Zhao H, Loh HH, Law PY (2006). Adenylyl cyclase superactivation induced by long-term treatment with opioid agonist is dependent on receptor localized within lipid rafts and is independent of receptor internalization. Mol Pharmacol 69: 1421-1432. 